\title{
OSM potentiates preintravasation events, increases CTC counts, and promotes breast cancer metastasis to the lung
}

Ken Tawara ${ }^{1}$, Celeste Bolin', Jordan Koncinsky' ${ }^{1}$ Sujatha Kadaba ${ }^{1}$, Hunter Covert ${ }^{1}$, Caleb Sutherland ${ }^{1}$, Laura Bond ${ }^{1}$, Joseph Kronz ${ }^{2}$, Joel R. Garbow ${ }^{3}$ and Cheryl L. Jorcyk ${ }^{1^{*}}$

\begin{abstract}
Background: Systemic and chronic inflammatory conditions in patients with breast cancer have been associated with reduced patient survival and increased breast cancer aggressiveness. This paper characterizes the role of an inflammatory cytokine, oncostatin M (OSM), in the preintravasation aspects of breast cancer metastasis.
\end{abstract}

Methods: OSM expression levels in human breast cancer tissue samples were assessed using tissue microarrays, and expression patterns based on clinical stage were assessed. To determine the in vivo role of OSM in breast cancer metastasis to the lung, we used three orthotopic breast cancer mouse models, including a syngeneic 4T1.2 mouse mammary cancer model, the MDA-MB-231 human breast cancer xenograft model, and an OSM-knockout (OSM-KO) mouse model. Progression of metastatic disease was tracked by magnetic resonance imaging and bioluminescence imaging. Endpoint analysis included circulating tumor cell (CTC) counts, lung metastatic burden analysis by $\mathrm{qPCR}$, and ex vivo bioluminescence imaging.

Results: Using tissue microarrays, we found that tumor cell OSM was expressed at the highest levels in ductal carcinoma in situ. This finding suggests that OSM may function during the earlier steps of breast cancer metastasis. In mice bearing MDA-MB-231-Luc2 xenograft tumors, peritumoral injection of recombinant human OSM not only increased metastases to the lung and decreased survival but also increased CTC numbers. To our knowledge, this is the first time that a gp130 family inflammatory cytokine has been shown to directly affect CTC numbers. Using a 4T1.2 syngeneic mouse model of breast cancer, we found that mice bearing 4T1.2-shOSM tumors with knocked down tumor expression of OSM had reduced CTCS, decreased lung metastatic burden, and increased survival compared with mice bearing control tumors. CTC numbers were further reduced in OSM-KO mice bearing the same tumors, demonstrating the importance of both paracrine- and autocrine-produced OSM in this process. In vitro studies further supported the hypothesis that OSM promotes preintravasation aspects of cancer metastasis, because OSM induced both 4T1.2 tumor cell detachment and migration.

Conclusions: Collectively, our findings suggest that OSM plays a crucial role in the early steps of metastatic breast cancer progression, resulting in increased CTCs and lung metastases as well as reduced survival. Therefore, early therapeutic inhibition of OSM in patients with breast cancer may prevent breast cancer metastasis.

Keywords: Oncostatin M, Breast cancer, Metastasis, Circulating tumor cells

\footnotetext{
* Correspondence: cjorcyk@boisestate.edu

${ }^{1}$ Department of Biological Sciences, Biomolecular Sciences Program, Boise

State University, 1910 University Drive, Boise, ID 83725, USA

Full list of author information is available at the end of the article
}

(c) The Author(s). 2018 Open Access This article is distributed under the terms of the Creative Commons Attribution 4.0 International License (http://creativecommons.org/licenses/by/4.0/), which permits unrestricted use, distribution, and reproduction in any medium, provided you give appropriate credit to the original author(s) and the source, provide a link to the Creative Commons license, and indicate if changes were made. The Creative Commons Public Domain Dedication waiver (http://creativecommons.org/publicdomain/zero/1.0/) applies to the data made available in this article, unless otherwise stated. 


\section{Background}

The inflammatory gp130 family of cytokines has been shown to modulate immune function [1] with important implications for tumor immunology [2]. Inflammation and inflammatory cytokines have been associated with increased breast cancer metastasis and poor survival rates [3]. Interleukin-6 (IL-6), a well-known inflammatory cytokine in the gp130 family, promotes breast cancer metastasis [4]. Other cytokines within the gp130 family also modulate inflammation. One such member, oncostatin M (OSM), has been associated with a wide variety of inflammatory disease states, such as in inflammatory bowel disease and arthritis $[5,6]$. In the context of cancer, OSM has been shown to induce in vitro effects associated with cancer invasiveness and to promote breast cancer metastasis to bone in vivo [7]. In the breast tumor microenvironment, OSM is produced by breast tumor cells [8], as well as by stromal cells, including tumor-associated macrophages and neutrophils [9, 10]. After the secretion of OSM, OSM binds to and accumulates in the extracellular matrix (ECM) in an active form. This accumulated OSM may then lead to chronic local inflammation and increased tumor metastasis [11]. Specifically, it has been shown that human breast tumor cells signal neutrophils to secrete OSM, which subsequently induces tumor cell vascular endothelial growth factor (VEGF) production, cell detachment, and invasive capacity [9]. Collectively, these studies suggest that OSM functions in breast cancer progression in both an autocrine and a paracrine fashion.

OSM signaling uses two dimeric receptors. OSM binds with high affinity to the OSM receptor (OSMR), which consists of a gp130 subunit and OSMR $\beta$, and with lower affinity to the leukemia inhibitory factor receptor (LIFR), which consists of gp130 and LIFR $\beta$ [12]. OSMR signaling initiates the JAK/STAT, mitogen-activated protein kinase (MAPK), and phosphoinositide 3-kinase/AKT pathways $[13,14]$, as well as the stress-activated MAPK p38 and JNK pathways [15]. Whereas OSM binding to the OSMR has been shown to promote cancer cell malignancy and reduce long-term survival in patients with breast cancer [16], LIF activation of the LIFR suppresses tumor growth and metastasis [17]. Activation of the LIFR by OSM promotes bone growth and may also suppress breast cancer metastatic phenotypes [12, 18].

As a pleiotropic cytokine, OSM appears to play an important role in promoting breast cancer metastatic potential in vitro while inhibiting breast tumor cell proliferation [19]. OSM has been shown to function in breast and various other cancer cells in culture to (1) promote an epithelial-to-mesenchymal transition (EMT) and a stem cell-like phenotype [14, 20]; (2) upregulate expression of proteases such as matrix metalloproteinases [21]; (3) promote tumor cell detachment and subsequent invasion [22, 23]; (4) induce the expression of VEGF, hypoxia inducible factor- $1 \alpha$, and other proangiogenic factors [24]; and (5) suppress estrogen receptor (ER)- $\alpha$ expression [16]. Despite increasing in vitro evidence, limited studies have addressed the role of OSM in breast cancer metastasis in vivo.

Our previous studies were the first to show the importance of OSM in breast cancer metastasis to bone. Specifically, reduced tumor cell-produced OSM expression led to a decrease in osteolytic bone metastasis in an orthotopic 4T1.2 mouse model [7]. Because it has been demonstrated that OSM functions in normal bone homeostasis [25], this work suggests an important role for OSM during postintravasation breast cancer metastasis to bone and subsequent bone destruction. Although in vitro studies suggest that OSM promotes the early steps of the metastatic cascade, no existing work differentiates between OSM's impact on pre- versus postintravasation aspects of the breast cancer metastatic cascade.

The work presented in this paper demonstrates that OSM initiates the preintravasation steps of the metastasis cascade, increases circulating tumor cell (CTC) numbers, promotes lung metastases, and decreases survival in mice. Conversely, we also show that OSM has no effect on survival in the postintravasation model that bypasses the early steps of metastasis by injecting tumor cells directly into the circulation. Collectively, our work suggests that therapeutic suppression of OSM in the tumor microenvironment not only might be an effective treatment strategy for bone metastasis but also could be used as a preventive therapeutic to mitigate overall breast cancer metastasis.

\section{Methods}

\section{Tissue microarrays}

Breast tissue from 72 patients was obtained from paraffin block archives at the Department of Pathology, Mercy Medical Center, Nampa, ID, USA. Three tissue microarrays (TMAs) of 1-mm thickness were assessed. The TMAs were stained for OSM using the Histostain kit (catalogue number 95-9843; Life Technologies, Carlsbad, CA, USA) per the manufacturer's instructions. The TMAs were deparaffinized and stained overnight with a 1:400 dilution of rabbit antihuman OSM primary antibody (catalogue number sc-129; Santa Cruz Biotechnology, Dallas, TX, USA) and for 1 hour with 1:1000 goat antirabbit IgG-alkaline phosphatase secondary antibody. TMAs stained with secondary antibody alone served as the negative control, and spleen and salivary gland served as positive controls for OSM staining. The TMAs were analyzed in multiple sets of random orders for OSM expression intensity by a pathologist and were graded as follows: $0=$ no staining; $1=$ light staining; $2=$ medium staining; and $3=$ dark staining. Grading for each 
patient was averaged for each cell tissue type (ductal epithelial, vessel, stroma). Additional methods are detailed in Additional file 1: Supplemental Materials and Methods.

\section{Cell lines and culture conditions}

MDA-MB-231-D3H2LN luc2 cells (Caliper Life Sciences, Waltham, MA, USA) and MDA-MB-231 human breast cancer cells (American Type Culture Collection, Manassas, VA, USA) were cultured in RPMI 1640 media supplemented with $10 \%$ FBS and $100 \mathrm{U} / \mathrm{ml}$ penicillinstreptomycin. Cells were maintained at $37{ }^{\circ} \mathrm{C}, 5 \%$ carbon dioxide, and 95\% humidity. 4T1.2 mouse mammary cancer cells [26] were cultured in $\alpha$-minimal essential medium ( $\alpha$-MEM) supplemented with 10\% FBS, $1 \mathrm{mM}$ sodium pyruvate, and $100 \mathrm{U} / \mathrm{ml}$ each of penicillin and streptomycin, and the cells were passaged for no more than 6 months. All media and supplements were obtained from HyClone Laboratories (Logan, UT, USA). All cell lines were tested for mycoplasma contamination by routine 4',6-diamidino-2-phenylindole staining, and experiments were accomplished within ten passages after cell line thawing.

\section{Plasmid construct design and cell transfection}

To transduce MDA-MB-231-Luc2-D3H2LN cells with a tetracycline (TET)-inducible vector, the full-length OSM complementary DNA was cloned into the pLenti6.3/TO/ V5-DEST vector (Life Technologies). Lentiviral transduction of the pLenti6.3/TO/V5-DEST+hOSM vector and pLenti3.3/TR vector was performed using the ViraPower $^{\text {Tit }}$ II Lentiviral Gateway Expression System (K36720; Life Technologies) in accordance with the manufacturer's instructions. Stably transduced cell lines were tested for TET induction of hOSM expression by enzyme-linked immunosorbent assay (ELISA) and Western blot analysis. To create OSM-knockdown 4T1.2 cells, OSM short hairpin RNA (shRNA) and a LacZ shRNA sequences were cloned into the pSilencer 4.1 plasmid (Life Technologies) and stably transfected into 4T1.2 cells as previously described [7]. Two viable OSM-knockdown 4T1.2 cell lines were generated using different shRNA constructs (4T1.2-shOSM1 and 4T1.2shOSM2) [7].

\section{ELISA}

OSM produced by TET-inducible MDA-MB-231 $\left(\mathrm{MDA}^{\mathrm{TO} / \mathrm{OSM}}\right)$ cells was tested for in vitro activity. $\mathrm{MDA}^{\mathrm{TO} / \mathrm{OSM}}$ cells were treated with $0.1 \mathrm{mg} / \mathrm{ml}$ TET for 48 hours to generate conditioned media (CM) containing OSM. The CM was then applied to parental MDA-MB-231, MDA-MB-231-Luc2, or T47D cells for 30 minutes. Respective cell lysates were then collected from treated cells using PathScan ${ }^{\circ}$ Sandwich ELISA Lysis
Buffer (catalogue number 7018; Cell Signaling Technology, Danvers, MA, USA). The lysates were then run on a PathScan ${ }^{\bullet}$ Phospho-Stat3 (Tyr705) Sandwich ELISA in accordance with the manufacturer's instructions (catalogue number 7146; Cell Signaling Technology).

To assess OSM concentration in animal serum, whole blood was collected from $\left(\mathrm{MDA}^{\mathrm{TO} / \mathrm{OSM}}\right)$ tumor xenograft animals at the experimental endpoint and allowed to coagulate for 30 minutes. The coagulated blood was centrifuged at $2500 \mathrm{rpm}$ for 10 minutes, and the upper layer was collected as serum. The serum was then diluted 1:3 in PBS and used in an hOSM ELISA (catalogue number DY295; R\&D Systems, Minneapolis MN, USA), which was performed in accordance with the manufacturer's instructions.

\section{Western blot analysis}

OSM was induced in $\mathrm{MDA}^{\mathrm{TO} / \mathrm{OSM}}$ cells for 48 hours with $0.1 \mathrm{mg} / \mathrm{ml}$ TET in 10\% FBS RPMI 1640 media. The $\mathrm{CM}$ was collected, run on a gel, and blotted onto 0.22$\mu \mathrm{m}$ polyvinylidene difluoride membranes (EMD Millipore, Billerica, MA, USA). Membranes were blocked using 5\% nonfat dry milk diluted in PBS at $\mathrm{pH} \quad 7.4$ with $0.05 \%$ Tween 20 (NFDM-PBS-T). Antihuman OSM antibody (catalogue number sc-129; Santa Cruz Biotechnology) was used at 1:1000 dilution in 5\% NFDM-PBS-T, and a secondary antirabbit horseradish peroxidase antibody (catalogue number 711-035152; Jackson ImmunoResearch Laboratories, West Grove, PA, USA) was used at 1:5000 dilution in 5\% NFDM- PBS-T.

\section{Animals and tumor cell injections}

All animal experiments were performed in accordance with the local institutional animal care and use committee (IACUCs). Six-week-old female athymic nude mice were used for the xenograft experiments, and 6-weekold female $\mathrm{BALB} / \mathrm{c}$ mice were used for the syngeneic studies. All mice were obtained from the National Cancer Institute's Animal Production Facility (Frederick, MD, USA). OSM-knockout (OSM-KO) BALB/c mice were backcrossed from OSM-KO C57BL/6 mice, which were a kind gift from Dr. Peter Donovan, indirectly, through Dr. James Ihle (St. Jude's Children's Hospital, Memphis, TN, USA). Animals were backcrossed for at least ten generations, and genotyping was done at each generation to ensure the presence of the knockout allele. Nonsurgical orthotopic injections were performed as described previously with $2.0 \times 10^{6}$ cells diluted in $50 \mu \mathrm{l}$ of PBS containing $10 \%$ medium for the xenograft model and with $1 \times 10^{5}$ cells for the syngeneic models [7]. For all animals, starting at 2 weeks postinjection, tumor length and width were measured with mechanical calipers three times per week, and tumor volume was 
estimated using the equation tumor volume $=($ length $\times$ width $\left.^{2}\right) / 2$. The survival endpoint was defined by the IACUC as tumor size greater than $20 \mathrm{~mm}$ in diameter, $10 \%$ or greater weight loss, and/or appearance of cachexia. At the experimental endpoint, animals were killed, and their organs were harvested and examined for any abnormalities. Further analysis specific to each model is described below.

For peritumoral OSM injections, either $50 \mu \mathrm{l}$ of PBS or $1 \mu \mathrm{g}$ of recombinant full-length human OSM (PeproTech, Rocky Hill, NJ, USA) diluted in $50 \mu \mathrm{l}$ of PBS was injected into the area surrounding the tumor three times per week until the endpoint of the experiment. When the tumors became palpable, mice were randomized into groups and began receiving peritumoral injections.

For the TET-OSM-inducible MDA-MB-231 $\left(\mathrm{MDA}^{\mathrm{TO} /}\right.$ $\mathrm{OSM}$ ) experiments, the OSM-induced group was given $2 \%$ sucrose water containing $0.1 \mathrm{mg} / \mathrm{ml} \mathrm{TET}$, whereas the control mice were given just $2 \%$ sucrose water until the endpoint of the experiment. To assess blood platelet numbers, blood was collected at the endpoint into ethylenediaminetetraacetic acid (EDTA)-coated tubes (BD Biosciences, San Jose, CA, USA), and a complete blood count was performed by WestVet Veterinary Clinic (Garden City, ID, USA).

\section{In vivo bioluminescence imaging and tumor progression}

Bioluminescence imaging (BLI) of live animals was initiated at 13 days after cell injection and performed weekly. Three to five mice were scanned at one time. Ex vivo organs were also scanned using BLI. Both procedures followed our previously described protocols [27].

\section{Detection of circulating tumor cells by Alu qPCR}

The detection of human CTCs in mouse blood was performed as described previously [28]. A human DNA standard curve was prepared by adding a specified number of human MDA-MB-231 cells into mouse blood, and the DNA was then isolated for use in the qPCR reactions (Additional file 2: Figure S1). Genomic DNA was isolated from $100 \mu \mathrm{l}$ of whole blood collected from mice at the end of the experiment. DNA was isolated using the DNeasy Blood \& Tissue kit (catalogue number 69581; Qiagen, Hilden, Germany) per the manufacturer's standard instructions. DNA concentrations were normalized between each sample, and $4.5 \mathrm{ng}$ of DNA was added to each $25-\mu \mathrm{l}$ qPCR reaction. The qPCR reaction mixture was obtained from the SYBR Green GoTaq qPCR Master Mix (catalogue number TM318; Promega, Madison WI, USA), and reaction mixtures were prepared in accordance with the manufacturer's recommendations. To each reaction, $0.125 \mu \mathrm{l}$ of $100 \mu \mathrm{M}$ human Alu and mouse glyceraldehyde 3-phosphate dehydrogenase $(G A P D H)$ primers were added. The primer sequences are listed in Additional file 1: Table S1. Reaction conditions were as follows: $50{ }^{\circ} \mathrm{C}$ for 2 minutes, $95^{\circ} \mathrm{C}$ for 3 minutes, and 40 cycles of $\left(95{ }^{\circ} \mathrm{C}\right.$ for 15 minutes, $60{ }^{\circ} \mathrm{C}$ for 30 minutes, and $72{ }^{\circ} \mathrm{C}$ for 30 minutes. Fluorescence measurements were taken during the annealing temperature stage $\left(60{ }^{\circ} \mathrm{C}\right)$. Cycle threshold $\left(\mathrm{C}_{\mathrm{t}}\right)$ values were determined, and the final results were normalized to mouse GAPDH signal levels to normalize any sample-tosample variance in total blood volume and efficiency in total DNA purification.

\section{Quantitative PCR}

For quantitative analysis of lung metastases, lungs dissected from mice bearing mammary tumors were snapfrozen in liquid nitrogen and pulverized into a fine powder. DNA was extracted using an NaCl-Tris-EDTA buffer $(100 \mathrm{mM} \mathrm{NaCl}, 10 \mathrm{mM}$ Tris- $\mathrm{HCl}, \mathrm{pH}$ 8.0, $1 \mathrm{mM}$ EDTA) containing $20 \mu \mathrm{g} / \mathrm{ml}$ proteinase $\mathrm{K}$ and purified by two phenol/chloroform (1:1 vol/vol) extractions followed by ethanol precipitation. The ratio of cancer cells to normal cells was quantified by measuring the neomycin resistance gene $\left(\right.$ neo $\left.^{\mathrm{r}}\right)$ DNA levels versus the vimentin DNA loading control, as described previously [29]. TaqMan PCR was performed on an Applied Biosystems 7500 real-time thermocycler (Thermo Fisher Scientific, Foster City, CA, USA). Probe and primer sequences are listed in Additional file 1: Table S1. The cycling conditions were as follows: $50{ }^{\circ} \mathrm{C}$ for $5 \mathrm{mi}$ nutes, $95{ }^{\circ} \mathrm{C}$ for 2 minutes, then 40 cycles of $95{ }^{\circ} \mathrm{C}$ for 1 minute and $60{ }^{\circ} \mathrm{C}$ for 45 seconds. Fluorescence was measured every cycle after the annealing step, and $C_{t}$ values were calculated. The data were analyzed using the $2^{-\Delta \Delta \mathrm{Ct}}$ method [30].

\section{In vivo magnetic resonance imaging}

In vivo MRI experiments were performed using a 4.7-T small-animal magnetic resonance imaging (MRI) scanner equipped with a DirectDrive ${ }^{\mathrm{Tx}}$ console (Agilent Technologies, Santa Clara, CA, USA). The instrument is built around an Oxford Instruments (Oxford, UK) magnet containing Magnex (Agilent Technologies, Yarnton, UK) actively shielded (21-cm inner diameter, $\sim 30 \mathrm{G} / \mathrm{cm}$, $200 \mathrm{~ms}$ rise time) gradient coils driven by International Electric Company (Helsinki, Finland) gradient power amplifiers. Respiratory-gated spin-echo MRI studies were collected using a Stark Contrast (Erlangen, Germany) $2.5-\mathrm{cm}$ birdcage radiofrequency coil. Prior to the imaging experiments, mice were anesthetized with isoflurane and were maintained on isoflurane $/ \mathrm{O}_{2}(1-$ $1.5 \% \mathrm{vol} / \mathrm{vol}$ ) throughout data collection. The animals' core body temperature was maintained at $37 \pm 1{ }^{\circ} \mathrm{C}$ by circulation of warm air through the bore of the magnet. During the imaging experiments, the respiration rates for all mice were regular and $\sim 2 \mathrm{~s}^{-1}$. 
Synchronization of MRI data collection with animal respiration was achieved with a home-built respiratory-gating unit [31], and all images were collected during postexpiratory periods. The imaging parameters were as follows: repetition time $=3$ seconds; echo time $=20$ milliseconds; field of view $=2.5 \mathrm{~cm}^{2}$; data matrix $=128 \times 128 ; \quad$ slice thickness $=0.5 \mathrm{~mm}$; number of averages $=4$. Lung tumors were manually segmented with ImageJ software (rsbweb.nih.gov/ij; National Institutes of Health, Bethesda, MD, USA), and the number and volume of all metastatic tumors were measured and recorded on an animal-by-animal basis as described previously [32, 33].

\section{Detection of circulating tumor cells (clonogenic assay)}

Colony-forming assays were performed to detect CTCs in mouse blood. At the endpoint of the animal experiment, whole blood was collected into EDTA-coated tubes via intracardiac puncture. Red blood cells (RBCs) were lysed with $\mathrm{RBC}$ lysis solution (155 $\mathrm{mM} \mathrm{NH}_{4} \mathrm{Cl}$, $10 \mathrm{mM} \mathrm{KHCO}_{3}, 0.1 \mathrm{mM}$ EDTA diluted in doubledistilled $\mathrm{H}_{2} \mathrm{O}$ ) for 4 minutes. The remaining cell mixture, containing white blood cells and CTCs, was spun down and washed twice with PBS. The cell pellet was then resuspended in $\alpha$-MEM with $10 \%$ FBS, then plated and incubated at $37{ }^{\circ} \mathrm{C}$ for $7-10$ days until colonies formed. The colonies were then fixed with $10 \%$ formalin in PBS for 15 minutes, stained with Coomassie blue, and counted.

\section{Epithelial-to-mesenchymal transition assay}

4T1.2 mouse mammary cancer cells were plated on a 6well plate to a confluence of $30 \%$ in $\alpha$-MEM with $10 \%$ FBS and $1 \%$ penicillin-streptomycin. Following a period of 24 hours to allow cells to adhere, $25 \mathrm{ng} / \mathrm{ml}$ recombinant mouse OSM (rmOSM) was added to appropriate wells. Photomicrographs were taken at a power of $100 \times$ at 24 and 48 hours to observe phenotypic EMT changes over the 2-day period.

\section{Cell migration assay}

4T1.2 cells were plated on 6-well plates to a confluency of $80 \%$ in $\alpha$-MEM with $10 \%$ FBS. After the cells attached overnight, a straight scratch on the cell monolayer was made with a sterile $1000-\mu$ l polypropylene pipette tip, and loose cells and debris were washed away with three sterile PBS washes. The cells were then treated with or without $25 \mathrm{ng} / \mathrm{ml} \mathrm{rmOSM}$ and imaged every day for 3 days on the same part of the scratch using negative phase-contrast microscopy. The images were then imported into ImageJ software, and raw unmigrated area was measured by calculating the number of pixels in the area with no migration. Relative migration intensity was calculated as migration intensity $=($ day 0 unmigrated area/day $n$ unmigrated area) -1 .

\section{Cell detachment assay}

4T1.2 mouse mammary cancer cells were plated on 24well tissue culture dishes to a confluency of $80 \%$ in $\alpha$ MEM with $10 \%$ FBS. The cells were allowed to attach overnight, and rmOSM (25 ng/ml; R\&D Systems) suspended in $\alpha$-MEM with $10 \%$ FBS was added to the cells. For up to 8 days, cells that were detached were collected and counted using a hemocytometer, and viable cells were detected by lack of trypan blue staining (catalogue number SV30084.01; HyClone Laboratories).

\section{Statistical analysis}

TMA mean staining values were analyzed with repeated measures in a mixed model framework using compound symmetric covariance within patients and cancer status as fixed effects. All other statistical comparisons between multiple groups were assessed by one- or two-way analysis of variance (ANOVA) using Tukey's posttest analysis. Comparisons between two groups were analyzed by Student's $t$ test (two-tailed, unpaired). The statistical analyses were performed using Prism version 5.0b (GraphPad Software Inc., La Jolla, CA, USA) or SAS version 9.1.3 (SAS Institute, Cary, NC, USA) software. Survival data were analyzed using the log-rank (Mantel-Cox) test. Significance denoted as ${ }^{*} p<0.05$, ${ }^{* *} p<0.01$, and ${ }^{* * *} p<0.001$.

\section{Results}

High OSM expression in ductal carcinoma in situ and invasive ductal carcinoma suggests autocrine signaling

To assess breast epithelial cell expression and location of OSM in human breast tumors, TMAs containing samples from 72 patients were analyzed by IHC. Interestingly, OSM staining intensity was higher in the ductal carcinoma in situ (DCIS) tissue than in normal tissue, whereas no staining was observed using the control secondary antibody (Fig. 1a). Representative images of staining intensity are shown in Additional file 3: Figure S2. Quantification of OSM levels from all sections showed that the mean staining intensity for normal adjacent tissue (1.33) was significantly lower than that of DCIS (2.00) and invasive ductal carcinoma (IDC) (1.66) tissues, whereas metastatic tissue (1.24) was statistically similar to normal tissue (Fig. 1b and Additional file 1: Table S2). Fibroblast OSM expression in the cancerous stroma was significantly lower (0.39 mean OSM staining) than in adjacent normal stroma (0.94 mean OSM staining) $(p<0.001)$ (Additional file 1 : Table S3). Additionally, OSM expression was significantly higher in patients with metastasis and those with a positive margin status than in those with a negative margin status (Additional file 1: Table S4). Similarly to stromal OSM expression, we found that endothelial cells of blood 

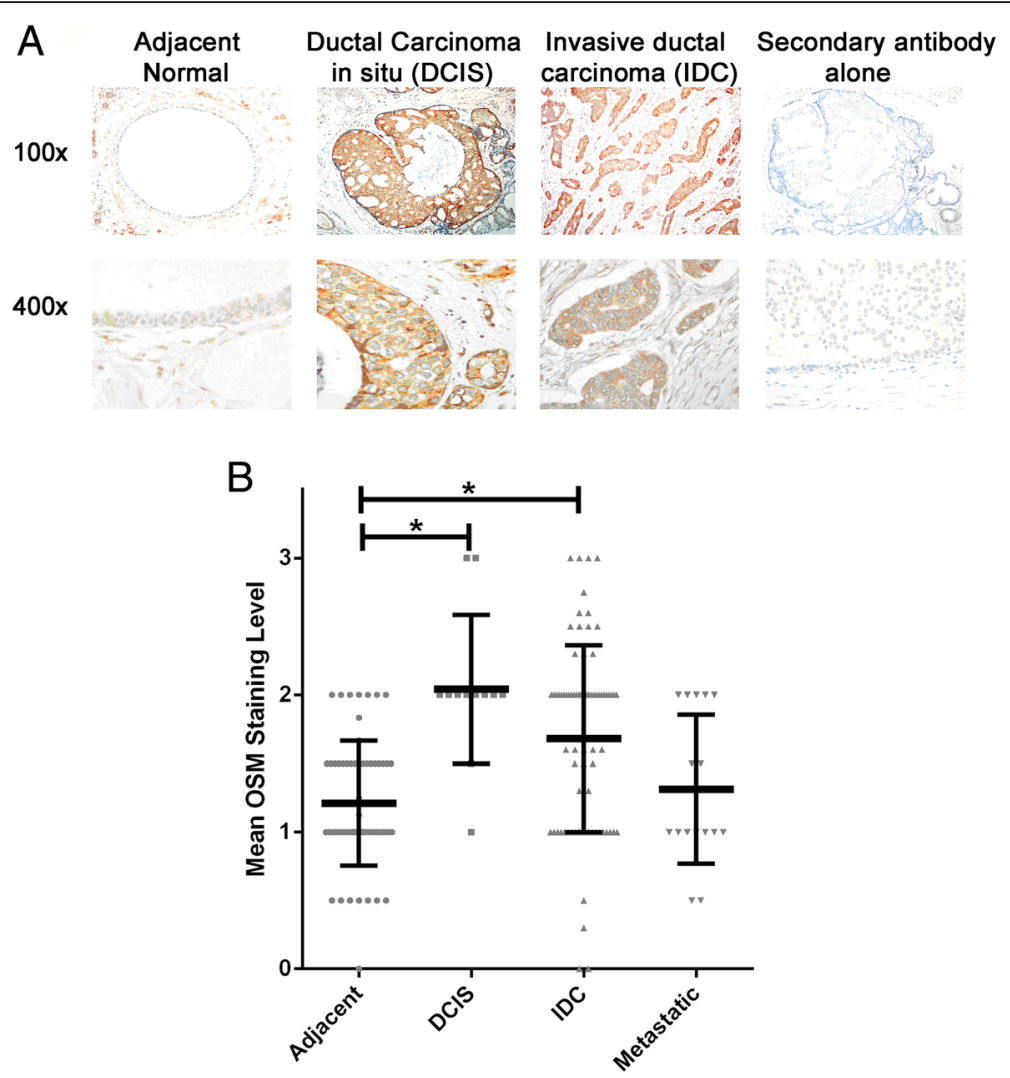

Fig. 1 Oncostatin M (OSM) is highly expressed in ductal carcinoma in situ (DCIS) and invasive ductal carcinoma (IDC). a To detect the presence of OSM in breast cancer tissue, histological microarrays from 72 patients with breast cancer were stained with human OSM antibody by IHC. Twelve patients had in situ DCIS, 54 patients had nonmetastatic IDC, and 16 patients had IDC with metastasis to lymph nodes (see Additional file 1). The results showed that normal adjacent tissue expresses little OSM but that OSM is highly expressed in DCIS and IDC. Secondary antibody alone did not produce any background signals. $\mathbf{b}$ Intensity quantification of OSM stained tissues. Mean staining intensity for DCIS (2.00) and IDC (1.66) tissues was significantly higher than that of normal adjacent tissue (1.33) and metastatic tissue (1.24). There was no statistically significant difference between normal and metastatic tissue. Multiple cores from the same patients were averaged. Data are expressed as mean \pm SD. ${ }^{*} p<0.05$ by one-way analysis of variance with Tukey's multiple comparisons test

vessels near the cancerous tissue had significantly lower OSM expression (1.22 mean OSM staining) than the blood vessel endothelium (1.66 mean OSM staining) around adjacent normal tissue $(p<0.001)$ (Additional file 1: Table S3).

On one hand, breast cancer subtype analysis of IHC staining revealed that OSM expression increased linearly with respect to HER2/Neu status in patients with IDC with increasing HER2/Neu expression (Additional file 1: Table S4). On the other hand, OSM expression levels did not change with respect to HER2/Neu in patients with metastatic disease (Additional file 1: Table S4). Additionally, OSM expression increased slightly (0.2) for every $50 \%$ increase in the expression of the ER in patients with IDC but did not change significantly in metastatic tissue. Together, these results suggest that OSM protein levels are higher in the earlier stages of breast cancer and that tumor cell-produced OSM may be important in autocrine signaling for the promotion of tumor progression. Although there is some indication that the expression of OSM is greater in ER+ and HER2+ breast cancer tissue samples, cell lines representing these subtypes have poor tumorigenic and metastatic capacity in vivo [34]. Furthermore, significant OSM expression is present in ER- and HER2/ Neu tumors. Therefore, we used metastatic in vivo models based on the MDA-MB-231-Luc2-D3H2LN cell line [35] and the highly metastatic 4T1.2 model, which are both ER-/HER2- $[7,26]$.

\section{Elevated production of OSM generated from TET-

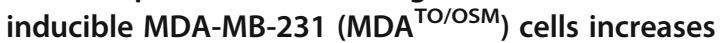
metastases to lungs and decreases overall survival

In order to assess the effects of cancer cell-produced OSM in a tumor microenvironment, we developed a stably transduced triple-negative breast cancer (TNBC) MDA-MB-231-Luc2-D3H2LN cell line that secretes OSM in response to TET treatment (+TET; $\mathrm{MDA}^{\mathrm{TO} / \mathrm{OSM}}$ ). MDA-MB-231-Luc2-D3H2LN cells have enhanced 
capacity to metastasize to multiple organs, including lung and bone, compared with the parental MDA-MB-231 cells, which have poor metastatic capacity via orthotopic application [35]. To compare the OSM produced by the $\mathrm{MDA}^{\mathrm{TO} / \mathrm{OSM}}$ cells with recombinant human OSM (hOSM), CM from MDA ${ }^{\mathrm{TO} / \mathrm{OSM}}$ cells treated with TET (0. $1 \mu \mathrm{g} / \mathrm{ml}$ ) was collected. MDA-MB-231, MDA-MB-231Luc, and T47D breast cancer cells were treated with either $\mathrm{CM}$ from $\mathrm{MDA}^{\mathrm{TO} / \mathrm{OSM}}$ cells or with rhOSM $(25 \mathrm{ng} / \mathrm{ml})$ for 30 minutes. OSM signaling was assessed by measuring STAT3 activation using a pSTAT3 ELISA. For each cell line investigated, there were no significant differences in the levels of pSTAT3 induced by OSM produced from TET-induced $\mathrm{MDA}^{\mathrm{TO} / \mathrm{OSM}}$ cells compared with rhOSM (Fig. 2a, left). Furthermore, the $\mathrm{CM}$ from $\mathrm{MDA}^{\mathrm{TO} / \mathrm{OSM}}$ cells treated with TET was assessed on an hOSM immunoblot, and an expected size band $(26 \mathrm{kDa})$ was detected (Fig. 2a, middle) by ELISA (Fig. 2a, right), showing an OSM concentration of $10 \mathrm{ng} / \mathrm{ml}$ in the CM.

To assess the activity of MDA ${ }^{\mathrm{TO} / \mathrm{OSM}}$ cells in vivo, $1 \times$ $10^{6}$ cells were injected into the fourth mammary fat pad of female athymic nude mice. The mice were given drinking water with TET (+TET) or without TET (-TET) $(0.1 \mathrm{mg} / \mathrm{ml}$ in $2 \%$ sucrose water) to induce OSM expression in the cancer cells. At the experimental endpoint, serum was then separated from whole blood, and serum OSM levels were assessed by ELISA. Tumorbearing mice +TET had a 67-fold higher level of OSM present in their serum than -TET mice (Fig. 2b, left). Each animal's physical condition was assessed, and animals with $\mathrm{MDA}^{\mathrm{TO} / \mathrm{OSM}}$ tumors + TET had significantly increased blood platelet counts (Fig. 2b, center). TETtreated mice also had a significant decrease in body weight compared with -TET mice (Fig. 2b, right; Additional file 4: Figure S3A), displaying a prominent spinal column and reduced apparent body fat, indicative of cachexia (Additional file 4: Figure S3B). It was previously reported that cachexia, elevated inflammatory factors, and kidney disease may be correlated with each other [36]. In this study, the cachexic animals had kidney abnormalities with hypoperfusion and damage to the gross morphological kidney structures (Additional file 4: Figure S3C). This correlated with +TET treatment and high levels of serum OSM in the animals (Additional file 4: Figure S3D and S3E), suggesting that high OSM levels may contribute to the development of cachexia and kidney dysfunction. Control animals without tumors treated with TET had normal body condition and normal kidney morphology (data not shown).

Additionally, in a separate experiment, animals were given TET drinking water for only 1 week so that we could assess the early effects of OSM on metastasis. Animals receiving 1 week +TET had higher levels of metastases to the lung than -TET mice, as assessed by ex vivo imaging, (Fig. 2c). Only sporadic spine or liver metastases were detected at this early time point (data not shown), which suggests that bone and liver metastases may grow more slowly or occur as a later event. This result also suggests that a short-term elevation in the level of OSM can promote the development of metastases to the lung. To measure animal survival, mice with $\mathrm{MDA}^{\mathrm{TO} / \mathrm{OSM}}$ tumors were treated with or without TET and allowed to progress to the endpoint. Mice given + TET drinking water had a mean decreased survival of 11 days compared with -TET mice (Fig. 2d). Collectively, these results demonstrated that elevated levels of tumor cell-produced OSM led to increased lung metastases, decreased survival, and deterioration in body condition indicative of cachexia.

OSM increases lung metastases and circulating tumor cell numbers in an orthotopic MDA-MB-231 model of breast cancer

To assess the paracrine effects of OSM, exogenous OSM was injected peritumorally in an orthotopic MDA-MB231 xenograft model. In this model, $2 \times 10^{6}$ MDA-MB231-Luc2-D3H2LN cells were injected into the fourth mammary fat pads of female nude mice. After the tumors were palpable $(\sim 3 \mathrm{~mm})$, OSM $(1 \mu \mathrm{g}$ in $50 \mu \mathrm{l}$ of PBS) or PBS alone was injected peritumorally three times per week, and mice were monitored until the endpoint criteria were met. Peritumoral injections can potentially cause supraphysiologic concentrations of OSM in the local tumor microenvironment, which may amplify any effect that OSM has on the tumor. However, in light of recent data suggesting that OSM accumulates in the acidic ECM, actual concentrations of inflammatory cytokines in the tumor microenvironment may be much higher locally than previously thought $[11,37]$. Unexpectedly, tumor volume did not differ between the groups (Fig. 3a), even though OSM has been shown to reduce MDA-MB-231 cell proliferation in vitro [38]. The BLI intensities of the tumors from both groups were similar (Fig. 3b), although a few mice in each group had lower BLI intensities owing to tumor necrosis.

Mice receiving peritumoral OSM showed larger metastatic volumes in both lung and spine than mice receiving PBS, as assessed by ex vivo imaging (Fig. 3c, left). Additionally, lungs dissected from the OSM-injected group had BLI intensities that were two orders of magnitude $\left(10^{2}\right)$ higher than those in the PBS-injected group (Fig. 3c, right). Similarly, spinal BLI intensity from OSM-treated mice averaged $2 \times 10^{7}$ photons/second, whereas control mice had a mean signal of $3 \times 10^{5}$ photons/second.

In patients with advanced and/or inflammatory breast cancer, high numbers of CTCs have been detected, suggesting a correlation between inflammatory factors and 

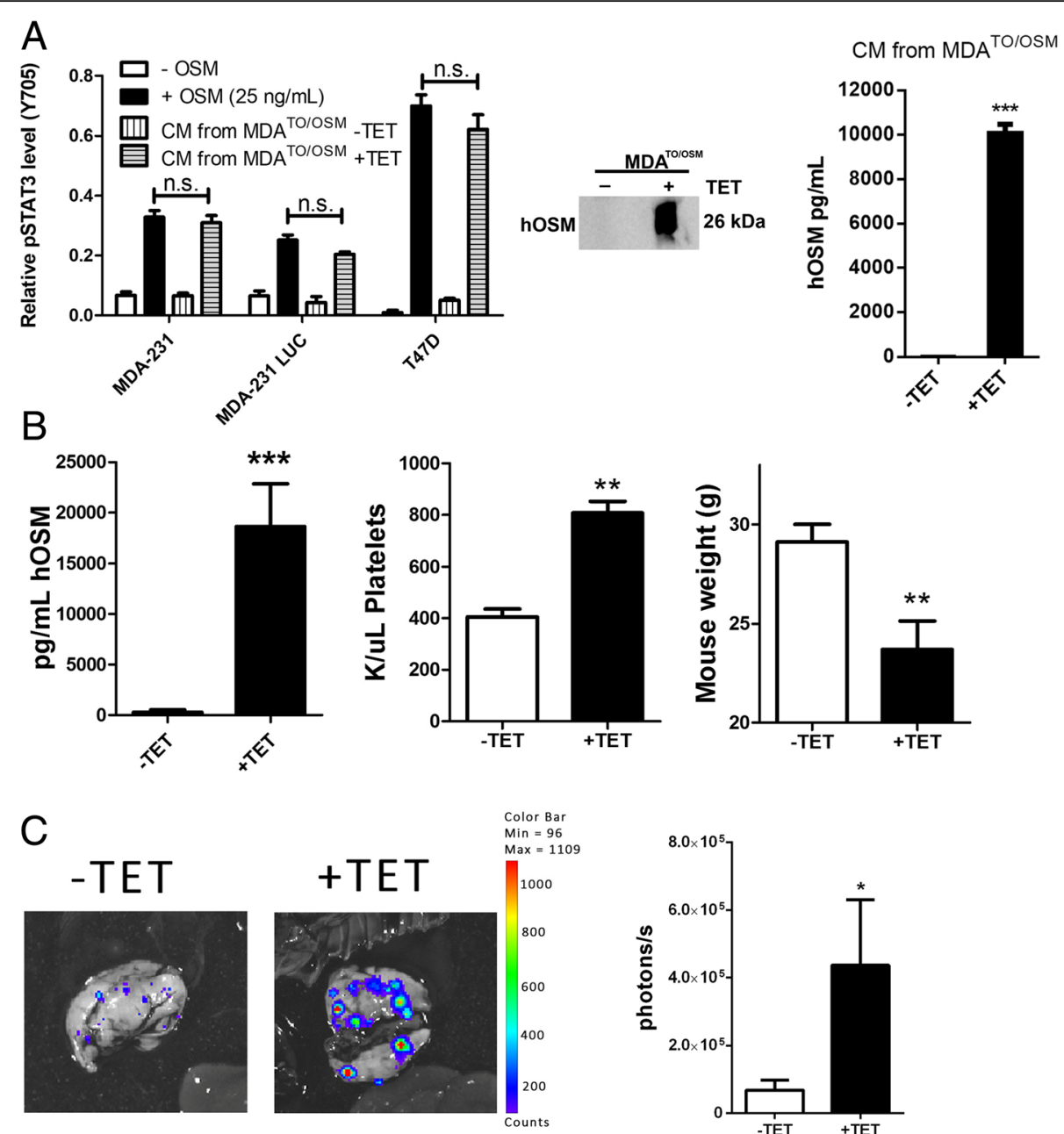

D
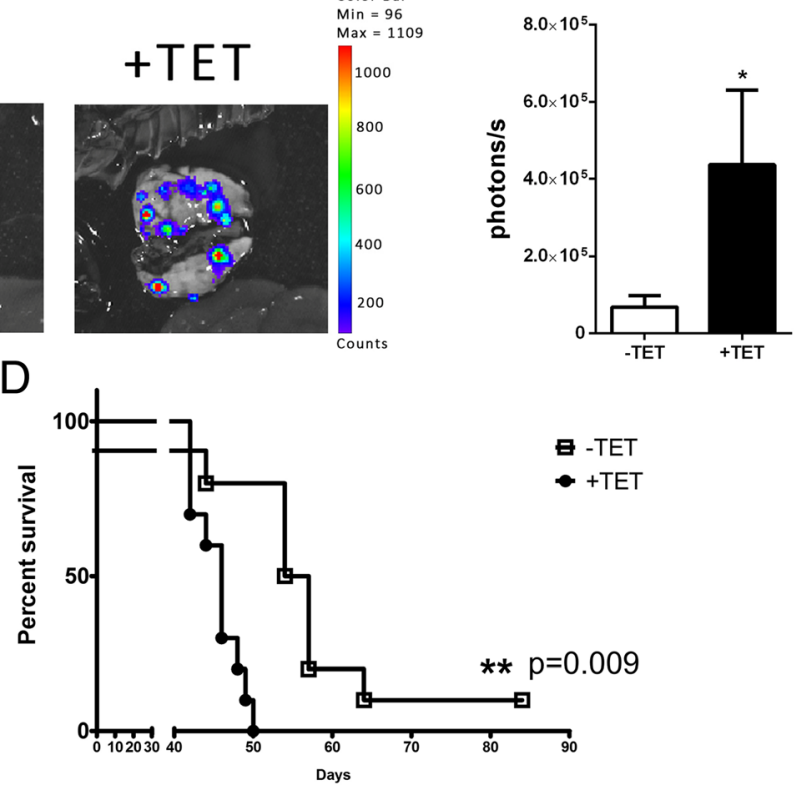

Fig. 2 (See legend on next page.) 
(See figure on previous page.)

Fig. 2 Oncostatin M (OSM) produced by tetracycline (TET)-inducible MDA-MB-231 (MDA $\left.{ }^{\mathrm{TO} / O S M}\right)$ cell MDA ${ }^{\mathrm{TO} / O S M}$ ) tumors increase metastasis and decrease survival. a MDA ${ }^{\mathrm{TO} / O S M}$ human breast cancer cells were treated with (+TET) or without TET (-TET), and the resultant conditioned media (CM) from the treated cells were applied to parental MDA-MB-231, MDA-MB-231-LUC, and T47D cells. Left: The activity of OSM accumulated in the CM was compared with commercially obtained recombinant human OSM (rhOSM) $(25 \mathrm{ng} / \mathrm{ml})$. There was no significant difference between OSM produced by MDA ${ }^{\text {TO/OSM }}$ versus rhOSM versus its ability to induce PSTAT3. Middle: Western blot analysis depicting that CM produced by MDA $^{\text {TO/OSM }}$ cells stimulated with TET contain OSM. Right: Enzyme-linked immunosorbent assay (ELISA) analysis showed that CM from TET-treated $\mathrm{MDA}^{\mathrm{TO} / O S \mathrm{M}}$ cells contain $10.1 \mathrm{ng} / \mathrm{ml}$ of hOSM. b Left: Animals with MDA ${ }^{\mathrm{TO} / \mathrm{OSM}}$ tumors were given drinking water with or without TET, and whole blood was collected at the experimental endpoint. After allowing the blood to clot and serum was separated by centrifugation, the resultant serum OSM levels were measured by ELISA. Animals with MDA TO/OSM tumors with drinking water containing TET had 67-fold higher serum OSM levels. Center: Platelet counts were higher in +TET MDA ${ }^{\text {TO/OSM }}$ tumor-bearing mice than in -TET mice. Right: +TET MDA ${ }^{\text {TO/OSM }}$ tumor-bearing mice had lower body weight than -TET mice. c Animals with MDA ${ }^{\text {TO/OSM }}$ tumors were given drinking water containing TET for 1 week, and their lung metastasis levels were assessed by ex vivo bioluminescence imaging. Left: Representative ex vivo bioluminescence image. Right: Average radiance analysis of the ex vivo bioluminescence imaging in photons per second per square centimeter per square radian $\left(\mathrm{p} / \mathrm{s} / \mathrm{cm}^{2} / \mathrm{sr}\right)$. Animals with $\mathrm{MDA}^{\mathrm{TO} / O S M}$ tumors +TET had a fivefold higher bioluminescent radiance than - TET mice $(-\mathrm{TET}, n=3 ;+\mathrm{TET}, n=6)$. Data are expressed as mean \pm SEM. d Kaplan-Meier survival curve for mice with MDA ${ }^{\text {TO/OSM }}$ tumors \pm TET. Mice that did not receive TET survived, on average, 11 days longer $(-\mathrm{TET}, n=9$; +TET, $n=10) .{ }^{* * *} p<0.001$ by log-rank test. Data are expressed as mean $\pm \mathrm{SEM} .{ }^{*} p<0.05,{ }^{* *} p<0.01$, and ${ }^{* * *} p<0.001$ by two-tailed $t$ test or one-way analysis of variance with Tukey's posttest where appropriate

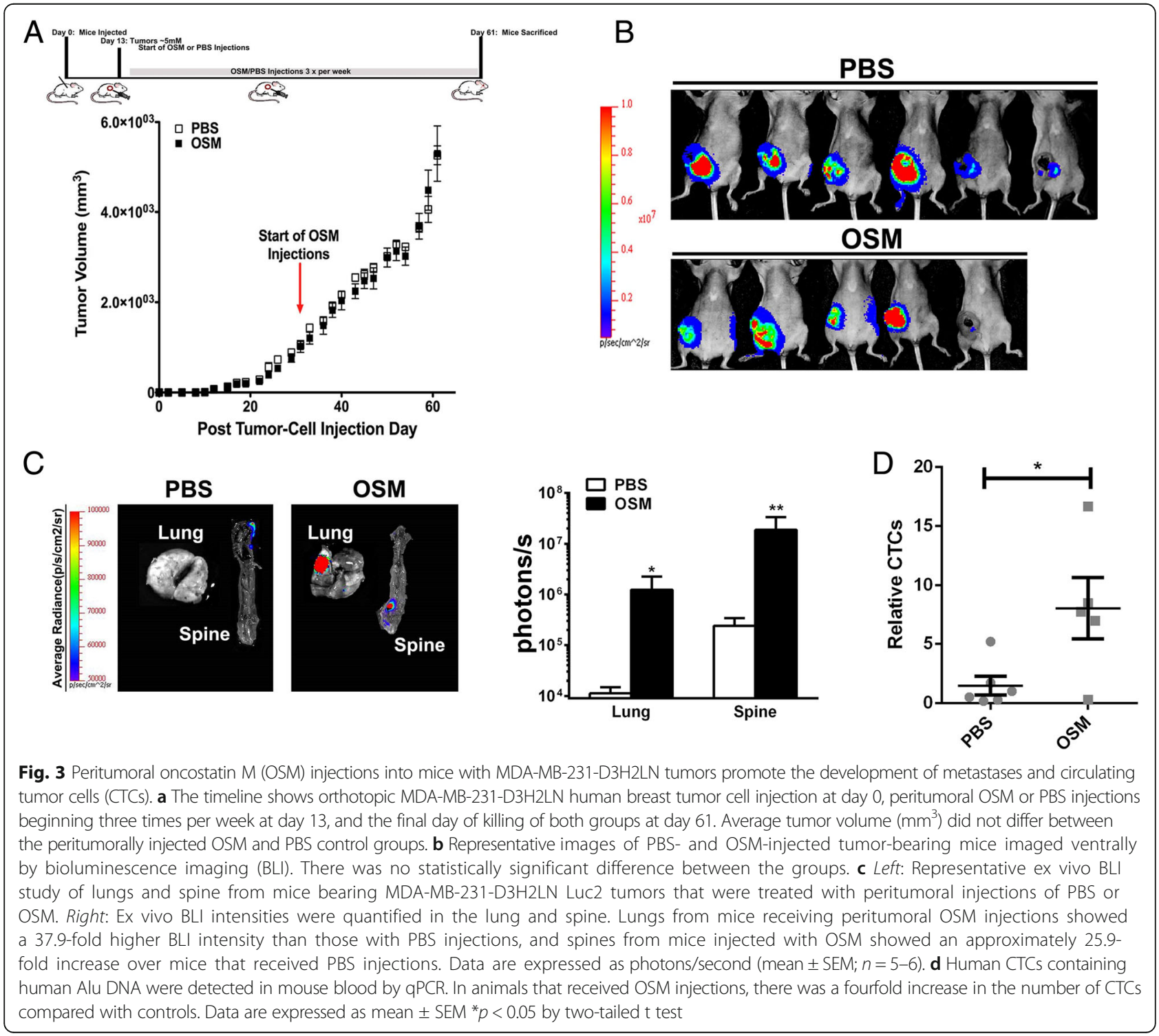


the number of CTCs [39]. In our xenograft model, both human MDA-MB-231-Luc2 tumor cells and potential CTCs contained multiple copies of human Alu DNA repeat sequences. To assess CTC numbers, DNA was isolated from mouse blood, and the levels of human Alu DNA repeat sequences were determined in the blood by qPCR. The resultant $C_{t}$ values were fitted to the standard curve to determine total CTC numbers in each sample (Additional file 2: Figure S1). In animals that received rhOSM injections, there was a fourfold increase in the number of CTCs per $100 \mu \mathrm{l}$ of mouse blood compared with animals that did not receive OSM (Fig. 3d). Collectively, this suggests that increased paracrine OSM in the tumor microenvironment increases metastasis to lung and spine while also increasing CTCs.

\section{Suppression of OSM in a syngeneic mouse model reduced lung metastases}

To use an immunocompetent mouse model, we employed two highly metastatic 4T1.2 mouse mammary tumor cell lines exhibiting knockdown expression of OSM in a syngeneic, orthotopic model of breast cancer
[7]. These two independent cell lines (4T1.2-shOSM1 and 4T1.2-shOSM2), developed from two independent shRNA constructs, were shown by ELISA to secrete a 3to 12-fold reduction in OSM, respectively, compared with control 4T1.2-LacZ cells [7]. To test the effects of OSM on mammary tumor metastasis in vivo, $1 \times 10^{5}$ control 4T1.2-LacZ, 4T1.2-shOSM1, and 4T1.2shOSM2 cells were injected orthotopically into the mammary fat pads of female BALB/c mice.

The mean number of relative lung metastases was shown to be tenfold lower in mice that received 4T1.2shOSM1 cells and fivefold lower in mice injected with 4T1.2-shOSM2 cells compared with 4T1.2-LacZ control cells (Fig. 4a). Histology performed on tissues from mice injected with parental 4T1.2 cells using an antimouse OSM antibody showed strong OSM expression in the primary mammary tumor, as well as some background expression in the normal breast connective tissue (Additional file 5: Figure S4). Specifically, very high OSM expression was seen at the leading edge of the primary mammary tumor, in closest proximity to the breast stroma.
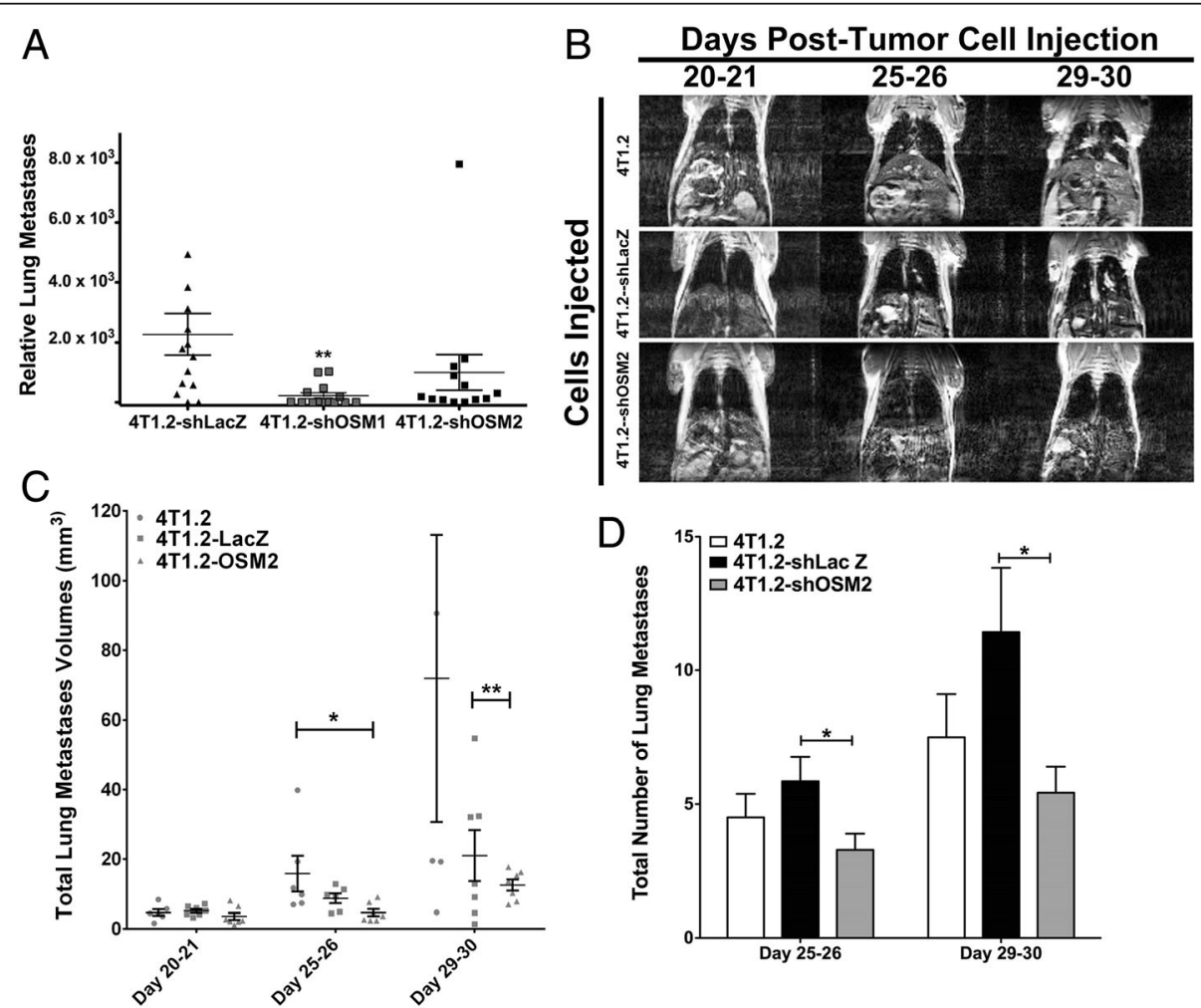

Fig. 4 Reduced oncostatin M (OSM) expression results in fewer spontaneous lung metastases and lower total volume of lung metastases by magnetic resonance imaging (MRI). a Lung metastasis burden was quantified by qPCR. Mice bearing mammary 4T1.2-shOSM1 or 4T1.2-shOSM2 tumors had less metastasis to the lung than mice with 4T1.2-shLacZ tumors. $\mathbf{b}$ Mice bearing 4T1.2-shOSM2 tumors had less metastatic lesions in the lung as detected by MRI at the endpoint of the experiment than mice bearing parental 4T1.2 or control 4T1.2-shLacZ tumors. MRI quantification of lung metastatic volume (c) and total number of lung metastases (d) showed significantly higher volume and number of lung metastases in the 4T1.2or 4T1.2-shLacZ-injected mice than the 4T1.2-shOSM2-injected mice (4T1.2, $n=6 ; 4 \mathrm{~T} 1.2$-shLacZ, $n=7 ;$ 4T1.2-shOSM2, $n=7$ ). Data are expressed as mean \pm SEM. ${ }^{*} p<0.05$ and ${ }^{* *} p<0.01$ by one-way analysis of variance with Tukey's multiple comparisons test 
MRI was used to track lung metastasis progression in vivo after injection of parental 4T1.2, control 4T1.2shLacZ, and 4T1.2-shOSM2 cells. Mice were scanned postinjection at days 20-21, days 25-26, and just before being killed at days 29-30 (Fig. 4b). For all three cell lines, MRI studies showed essentially no detectable metastasis at days 20-21. However, at 25-26 days and 29-30 days, readily identifiable metastases were observed in lung images. The average metastasis volume was significantly decreased, by $50-80 \%$, in $4 \mathrm{~T} 1.2-$ shOSM2 cells compared with 4T1.2-shLacZ control or parental 4T1.2 cells, respectively (Fig. 4c). There were also significant differences between the parental 4T1.2 cells and the control 4T1.2-shLacZ cells, which may be due to the potential off-target effects of shRNA activation [40-42]. This highlights the importance of using a true nontargeting shRNA control such as the 4T1.2shLacZ cells because shRNA activation alone appears to have cell-static effects in cancer cells [40].

Further analysis revealed that the total number of metastases was also reduced by more than $50 \%$ in mice injected with 4T1.2-shOSM2 cells compared with control 4T1.2-shLacZ cells at 25-26 days and 29-30 days (Fig. 4d). Thus, in vivo MRI confirmed that OSM may be a potent inducer of the metastatic cascade that results in lung metastases originating from a primary mammary tumor. In sum, these results suggest that OSM is necessary for spontaneous mammary tumor metastasis to the lung in a syngeneic mouse model.

\section{Suppression of OSM by shRNA increases survival from spontaneous metastasis via orthotopic injection but not via intracardiac injection in vivo}

We used a tumor resection survival model to mimic surgical removal of the primary tumor in patients and to determine if suppression of tumor-produced OSM limits early metastases. Orthotopic mammary fat pad injections were performed using control 4T1.2-shLacZ cells, 4T1. 2-shOSM1 cells, and 4T1.2-shOSM2 cells. Primary tumors were resected when they became palpable at day 14 (Fig. 5a), and mice were monitored until endpoint criteria were met (see the Methods section above). The mean survival time of the mice that received 4T1.2shOSM1 and 4T1.2-shOSM2 cell injections significantly increased, by 5 and 10 days, respectively, compared with animals with 4T1.2-shLacZ tumors (Fig. 5a). These results suggest that following primary mammary tumor resection, decreased OSM expression in primary tumor cells leads to increased survival.

In order to determine if OSM affects postintravasation aspects of metastasis, we injected the mammary tumor cells directly into the circulatory system via the left ventricle of the heart. There was no statistical difference in the survival time between mice injected intracardially with 4T1.2-shLacZ versus 4T1.2-shOSM2 cells (Fig. 5b). Similarly, there was no statistical difference in lung metastatic burden in the two different tumor types as assessed by qPCR (Additional file 6: Figure S5). These results suggest that tumor cell OSM expression has little effect on the postintravasation aspects of metastasis to lung, such as extravasation and metastatic site implantation.

\section{CTC number and metastatic burden is reduced in OSM- knockout mice compared with wild-type mice}

To determine if knocking out OSM in the whole organism affects CTC numbers in the 4T1.2 mouse model, wild-type and OSM-KO BALB/c mice were orthotopically injected with either 4T1.2-shLacZ or 4T1.2shOSM2 cells. Whole blood was collected at the endpoint, RBCs were lysed, and the remaining white blood cells containing the epithelial CTCs were examined using a clonogenic assay (Fig. 5c). Blood from control mice with no tumors had no colony formation (Additional file 7: Figure S6). Blood from OSM-KO mice injected with 4T1.2-shOSM2 cells had 15-fold fewer CTCs and 2.5-fold fewer lung metastases than wild-type mice injected with control 4T1.2-shLacZ cells (Fig. 5d, left). Additionally, OSM-KO mice bearing 4T1.2-shLacZ tumors had 10-fold fewer CTCs and 2.5-fold fewer lung metastases than wild-type mice with the same tumor type (Fig. 5d, right). In a separate in vitro assay to test the level of colony formation, there were no differences in colony numbers between the cell lines when seeded at low numbers ( 10 cells) (Additional file 8: Figure S7), which indicates that the OSM-knockdown cells do not have reduced ability to survive and develop colonies. These results suggest that microenvironment OSM, independent of tumor cell-secreted OSM, has a large effect on tumor cell dissemination into the circulation. Furthermore, this highlights the importance of paracrine OSM in breast cancer progression and metastasis.

\section{OSM increases preintravasation metrics of metastatic capacity in $4 \mathrm{~T} 1.2$ cells}

For tumor cells to enter the bloodstream as CTCs and subsequently metastasize, it is thought that they must first undergo EMT, followed by detachment, migration, and intravasation into the circulatory system [43]. Although OSM has been shown to increase tumor cell detachment and migration and to induce EMT in human breast cancer cell lines [16, 20-22, 44], no data have been published on murine $4 \mathrm{~T} 1.2$ cells in relation of OSM's in vitro effects. TNBC (ER-, PR-, HER2-) 4T1.2 mouse mammary cancer cells were treated with OSM (25 ng/ml) for 24 to 48 hours. On one hand, because 4T1.2 cells are an aggressive mesenchymal mammary cancer cell type, OSM did not affect cell morphology or 


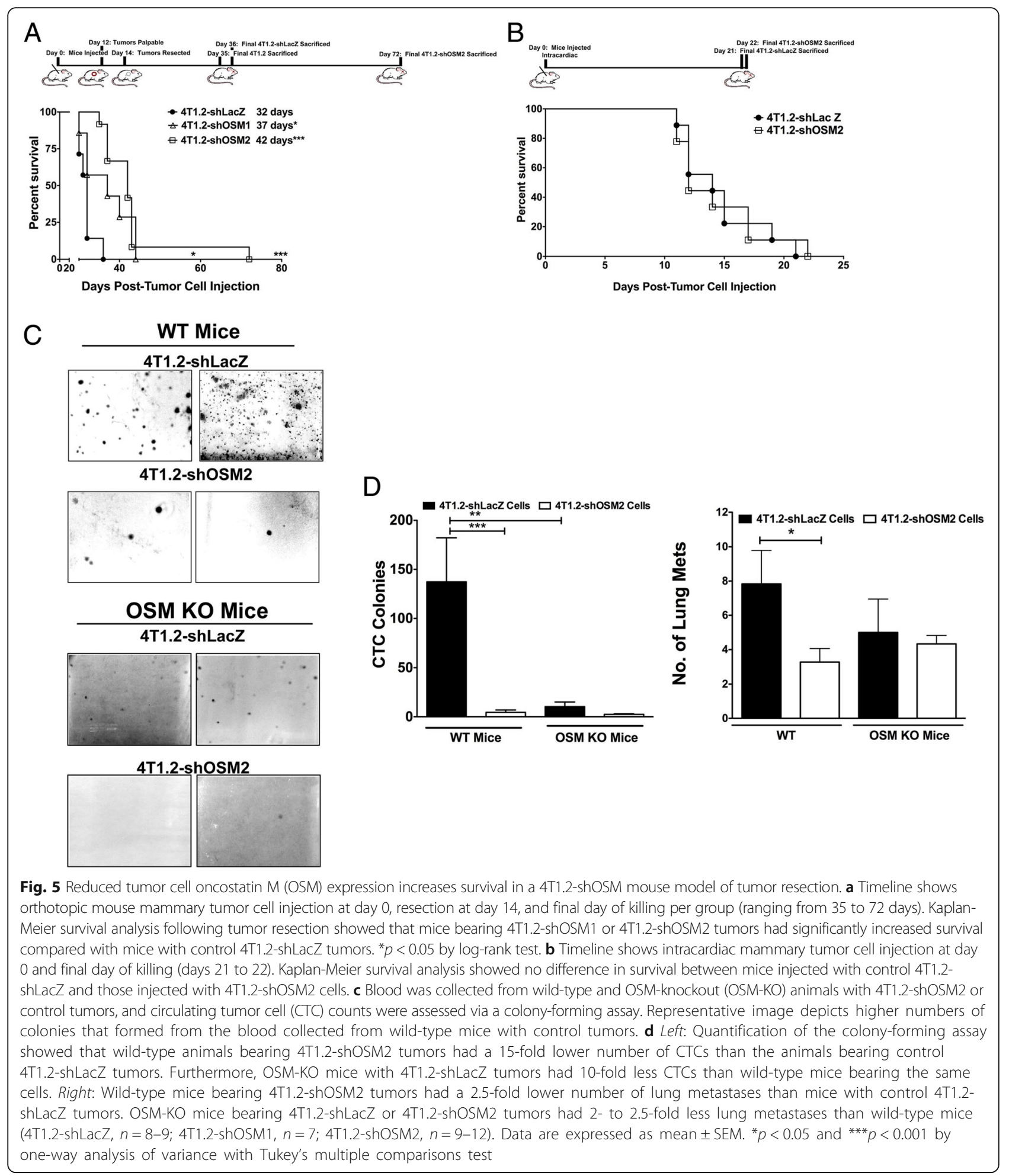

produce an EMT in vitro (Fig. 6a). On the other hand, OSM significantly increased 4T1.2 mammary tumor cell migration 7 -fold by day 3 in a cell migration assay (Fig. 6b) and tumor cell detachment 100-fold by day 8 (Fig. 6c). Our previous studies also demonstrated that OSM increases overall invasive potential in 4T1.2 cells [7]. These increases in migration and detachment were seen despite a $20 \%$ inhibition by OSM on 4T1.2 cell proliferation (Additional file 9: Figure S8). Together, these results suggest that OSM 

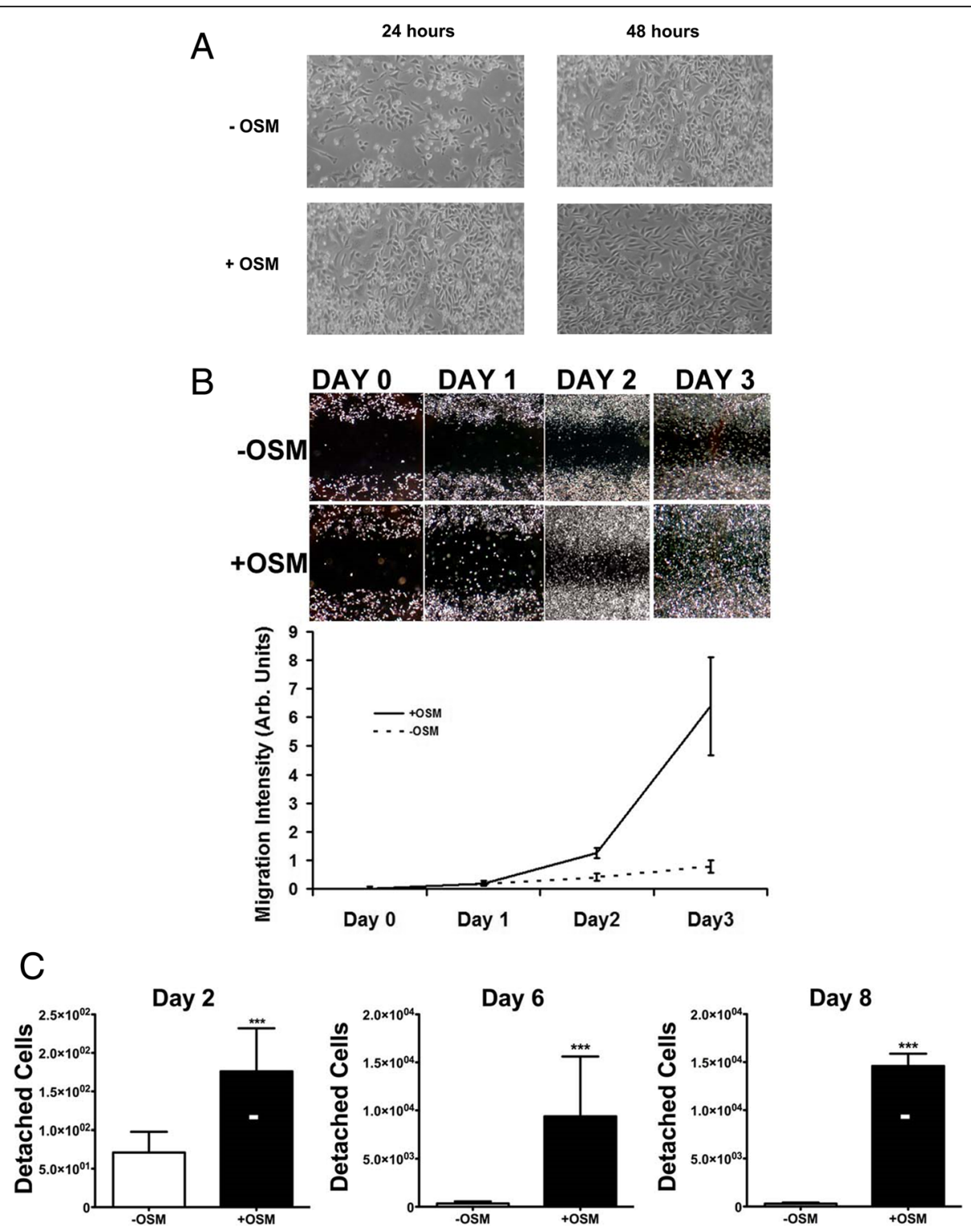

Fig. 6 Oncostatin M (OSM) promotes 4T1.2 cell detachment and migration. a 4T1.2 mouse mammary cancer cells were plated and treated with recombinant murine OSM $(25 \mathrm{ng} / \mathrm{ml})$ for 24 and 48 hours. No morphological changes indicative of epithelial-mesenchymal transition were detected. b 4T1.2 cells were grown to $80 \%$ confluence, and a uniform scratch was made. Cells treated with OSM had higher levels of migration than untreated controls (sevenfold by day 3). c A detachment assay was performed on 4T1.2 cells, and the number of detached cells was quantified. Cells treated with OSM had significantly higher numbers of detached cells (100-fold at day 8 ). Data are expressed as mean \pm SEM. ${ }^{*} p<0.05$ and ${ }^{* * *} p<0.001$ by two-tailed Student's $t$ test

may promote tumor cell dissemination into the circulation by increasing cell migration and detachment, which may subsequently increase the number of CTCs.

\section{Discussion}

In this paper, we show that OSM, whether acting in a paracrine fashion or produced by breast tumor cells and acting in an autocrine manner, can potentiate preintravasation metastatic events, such as migration, detachment, and increased CTCs (Fig. 7). Recent studies suggest that cells from DCIS can actually metastasize prior to their development into malignant IDC, though what triggers this early event has not been well characterized [45]. Our breast cancer IHC studies using TMAs resulted in an intriguing finding: OSM expression is highest in the epithelium of DCIS, as compared with IDC, metastatic, or adjacent normal tissue, though OSM levels in IDC are also high. When looking at the adjacent stroma, we found reduced levels of OSM in the fibroblasts and blood vessels of IDC tissues compared with normal 


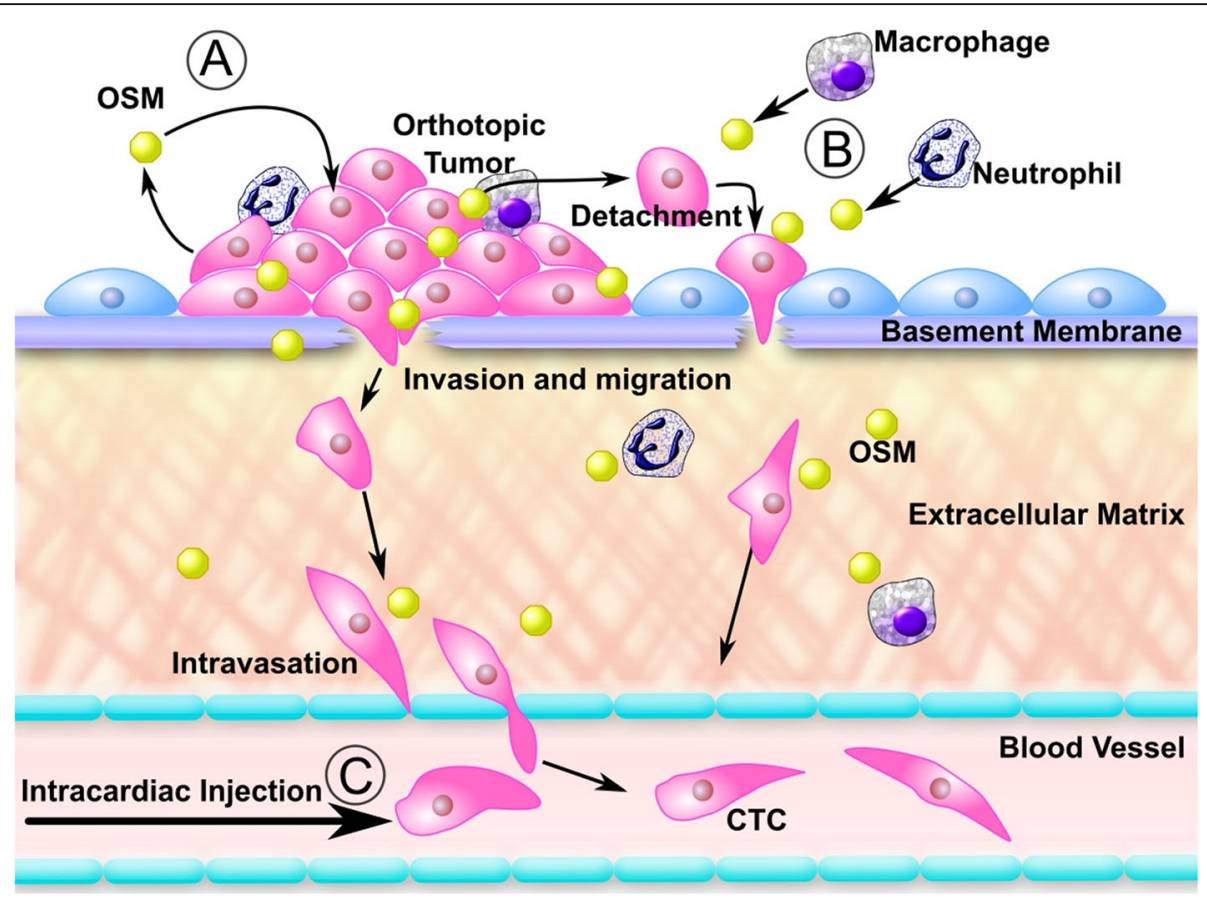

Fig. 7 Model of oncostatin M (OSM)-mediated metastasis. OSM is produced in an autocrine fashion by tumor cells (a), as well as by tumor-associated macrophages and neutrophils (b), for paracrine signaling. OSM promotes preintravasation effects, such as tumor cell detachment and migration, that can drive tumor cell intravasation into the circulation to develop circulating tumor cells and eventually metastasis. c When tumor cells are injected directly into the circulatory system, they bypass the multistep preintravasation aspects of metastases, and our data suggest that OSM has little effect on their extravasation and colonization at a secondary site

tissue. On one hand, this is interesting because we have previously shown that secreted OSM binds to proteins of the ECM and bioaccumulates in the tumor's acidic microenvironment [11]. On the other hand, GarcíaTunón et al. observed higher levels of breast tissue OSM and OSMR in IDC than in DCIS or normal tissue [8]. Although this finding differs somewhat from our study in relation to the stage at which the highest level of OSM was seen, there is agreement that higher OSM levels were detected in cancerous tissue than in normal tissue.

In this study, three different TNBC mouse models were used: One was an immunocompetent BALB/C model using syngeneic $4 \mathrm{~T} 1.2$ cells, and two were immunosuppressed athymic xenograft mouse models, using either MDA-MB-231-Luc2 or $\mathrm{MDA}^{\mathrm{TO} / \mathrm{OSM}}$ cells. Despite the differences between the systems used in our study, our results were consistent in that suppression of OSM reduced metastasis in BALB/c mice and injection of recombinant hOSM or TET-induced hOSM expression in $\mathrm{MDA}^{\mathrm{TO} / \mathrm{OSM}}$ cells increased human breast tumor metastasis in athymic mice. Although adaptive immunity is stunted in athymic mice owing to nonfunctional $\mathrm{T}$ cells, innate immune function is still intact [46]. Recent studies indicate that innate immunity plays a primary role in controlling progression of tumor growth and metastatic disease [47], and innate immune cells such as macrophages home to hypoxic tumors and promote angiogenesis [10]. OSM has recently been shown to increase the tissue infiltration of both the proinflammatory M1 and the wound-healing M2 macrophages [48]. Specifically, Lauber et al. demonstrated that OSM promotes lung metastatic burden in melanoma through M2 macrophage infiltration [49]. Thus, OSM may be promoting prometastatic responses, mediated by innate immunity, in the tumor microenvironment of both athymic and BALB/c mouse models to promote metastases.

Although the traditional cause of mortality in patients with advanced cancer is metastasis to vital organs, cachexia has been shown to contribute up to $50 \%$ of cancer patient deaths [50]. Significant weight loss as a consequence of fat loss and muscle wasting, indicative of cachexia, was seen in our TET-induced OSM in $\mathrm{MDA}^{\mathrm{TO} / \mathrm{OSM}}$ xenograft mouse model. TET alone does not appear to have any effect on kidney function [51]. Interestingly, TET has been shown to actually reduce tumor cell growth and aggressiveness [52], but this effect was not seen in our studies. Other studies have shown that high levels of various inflammatory cytokines, such as IL-6, potentiate loss of adipose tissue and muscle wasting [53]. Therefore, OSM may be yet 
another cytokine that could exacerbate cachexia in patients with breast cancer. In this study, mice with 4T1.2shOSM1 tumors had the lowest lung metastatic burden despite the fact that 4T1.2-shOSM2 cells have lower OSM expression [7]. However, this reduced lung metastasis in 4T1.2-shOSM1 tumor-bearing mice did not translate to increased survival for 4T1.2-shOSM2 tumor-bearing mice. This supports the notion that metastatic burden may not be the only cause of increased mortality, but that elevated cytokine levels may contribute to reduced survival. Furthermore, because cytokines modulate the immune system, it is very probable that cancer cachexia is related to maladaptive immune responses [54]. Interestingly, there were also major differences between the parental 4T1.2 cells and the control 4T1.2-shLacZ cells, where the shLacZ cells had significantly reduced lung metastasis volume. This highlights the importance of using a nontargeting shRNA control cells because shRNA activation has been known to have multiple off-target effects leading to reduced cell survival, metastasis, and growth $[40-42,55]$.

Platelets, as an adjunct to their classical role in thrombosis, are also important in mediating inflammation and immune response [56]. We found that in the $\mathrm{MDA}^{\mathrm{TO} /}$ OSM mouse model, higher OSM levels were correlated with increased platelet counts and reduced animal survival. Previous studies in patients with breast cancer have shown that elevated platelet counts were associated with poor prognosis and reduced disease-free survival [57]. Platelets have also been implicated in the promotion of metastasis by acting as a reservoir for factors that induce invasion and function to protect CTCs from the immune system [58]. In our study, increased viable CTCs were detected in our mouse models when higher levels of OSM were present, which may have been due to the elevated levels of platelets in circulation.

The ability of tumor cells to intravasate into the circulation directly correlates with CTC numbers from the corresponding tumor [59]. Increased CTC numbers have been linked clinically to enhanced metastatic burden in patients and a reduced 5-year survival rate [60]. Because tumors may shed early during cancer development [61], the detection of CTCs would be an important tool in the clinic to assess the metastatic capacity of a tumor, even as early as in precancerous DCIS. Typically, CTCs are detected using cancer epithelial markers, such as cytokeratins 18/19 [62]. However, highly aggressive tumor cells that have already undergone EMT, and thus have lost their epithelial markers, may evade detection [63]. Other possibly viable markers for CTC detection include epithelial cell adhesion molecule and human mammaglobin A [62]. For our studies, the highly aggressive mesenchymal-like MDA-MB-231 cells show negative or low expression for each of these markers, making conventional CTC detection unfeasible [63]. Thus, we employed multiple techniques that are markerindependent, such as the colony-forming assay for the mouse mammary tumor model or a PCR assay targeting human Alu sequences in the human breast tumor model. We did not use the colony-forming assays to assess the human breast tumor model, because the MDAMB-231 cells have a highly variable in vitro survival rate when seeded at low numbers. $4 \mathrm{~T} 1.2$ cells showed no difference in the overall level of cell survival when seeded at low numbers in vitro, which makes the colonyforming assay ideal for the 4T1.2 tumor model.

In our studies, suppression of tumor-produced OSM or the absence of OSM in OSM-KO mice resulted in reduced numbers of CTCs, whereas injection of recombinant OSM increased CTCs. There was no significant difference in the number of CTCs with or without TET in the $\mathrm{MDA}^{\mathrm{TO} / \mathrm{OSM}}$ mouse metastasis model (data not shown). This suggests that paracrine OSM may be more important than autocrine-produced OSM for CTC development. Indeed, in our OSM-KO mouse model, where there is less paracrine OSM, total CTC numbers and lung metastatic burden were significantly reduced compared with WT mice. Although the number of CTCs appeared modest in our study, these numbers are actually higher than the low numbers of CTCs seen in previously published studies $[64,65]$. It has been reported that even in advanced cancers, there can be as few as 1-5 CTCs per $7.5 \mathrm{ml}$ [66]. Our higher CTC numbers may point to differences in human and mouse physiology and may explain the much more rapid progression of metastatic disease seen in mice than in patients.

To assess some of the early aspects of metastasis that could lead to generation of CTCs in vitro, tumor cell EMT, migration, and detachment were studied in the highly aggressive 4T1.2 tumor model. 4T1.2 mammary tumor cells, which are considered analogues of highgrade human TNBC, have already undergone EMT, and OSM did not cause additional EMT-like effects [67]. However, our results show that OSM does increase cell migration, detachment, and invasion in 4T1.2 cells [7], supporting the idea that OSM operates in the preintravasation steps of metastasis. Other OSM-related factors, such as IL-6 and IL-8, may promote CTCs by increasing tumor cell invasion, detachment, and EMT [68]. Furthermore, these effects may be amplified in vivo because OSM possesses a proclivity to accumulate in the acidic ECM of the tumor microenvironment [11].

On the basis of our findings, OSM may potentiate the preintravasation aspects of the metastatic cascade to increase metastasis to the lung and bone [7]. This is evidenced by the fact that intracardiac injection of $4 \mathrm{~T} 1.2$ cells with reduced OSM (4T1.2-shOSM2) into mice, 
which bypasses the intravasation step of the metastatic cascade, did not result in increased survival compared with control cells (4T1.2-shLacZ). Therefore, it is highly probable that OSM functions before intravasation during cancer progression and suggests that OSM does not affect CTC survival, tumor cell extravasation, and/or secondary tumor growth.

\section{Conclusions}

The results of this study suggest that OSM increases lung metastases and CTC numbers by acting on early metastatic events (Fig. 7). Specifically, OSM increases tumor cell migration, detachment, and invasion [7], supporting the idea that OSM operates in the preintravasation steps of metastasis. Inhibition of OSM and/or OSMR has demonstrated antitumor effects and has recently been receiving increased attention as a possible cancer therapy [69, 70]. However, to our knowledge, no small-molecule inhibitors or humanized antibodies that target OSM signaling are in clinical trials for metastatic breast cancer. Taken together, the findings of this study provide a rationale for the administration of anti-OSM therapeutics before tumor resection, at the earlier stages of the disease, when the potential to improve overall survival of patients with breast cancer is greatest.

\section{Additional files}

Additional file 1: Table S1. Primer and probe sequences used for $\mathrm{QPCR}$ assay for the detection of CTC in blood obtained from tumor-bearing mouse. Table S2. Table format data for Fig. 1B show total number of patients and cores for each stage of breast tissue assessed. Table S3. Mean expression levels are statistically significantly different among cancerous and normal tissues for both stroma and blood vessel endothelium ( $p<.001)$. Table S4. Margin status, Her2/neu status and estrogen receptor (ER) status, were revealed by repeated measures analysis. Mean expression levels are statistically significantly different among cancerous, normal, and metastatic tissues for margin status, and ER status. For Her2 status, significant differences were found among cancerous, normal and between 0 and 1 staining intensity for metastatic tissues ( $p<.001)$. (DOCX $343 \mathrm{~kb}$ )

Additional file 2: Figure S1. qPCR standard curve derived from spiking cancer cells into mouse blood. MDA-MB-231 cells were spiked into mouse blood, and DNA was extracted and subjected to GPCR analysis. Specific cell numbers were correlated to $C T$ values and were used to construct a standard curve for the $C T$ values extrapolated from experimental mouse blood. (PPTX $186 \mathrm{~kb}$ )

Additional file 3: Figure S2. Representative OSM staining intensity in IHC. $0=$ no staining (image not shown), $1=$ light staining, $2=$ moderate staining, 3 = heavy staining. (PPTX $27 \mathrm{~kb}$ )

Additional file 4: Figure S3. Deterioration of physical condition in $\mathrm{MDA}^{\mathrm{TO} / \mathrm{OSM}}$ tumor-bearing mice treated with TET. a MDA ${ }^{\mathrm{TO} / \mathrm{OSM}}$ tumorbearing mice treated with tetracycline (+TET) lost, on average, $11.4 \%$ of their body weight during TET treatment, compared with -TET mice, which gained an average of $5.5 \%$ of their body weight over the same period. $\mathbf{b}$ Representative image of mice with $\mathrm{MDA}^{\mathrm{TO} / \mathrm{OSM}}$ tumors + TET shows prominent spinal column, muscle wasting, and lack of visible adipose tissue. c Gross morphology of normal (left) and abnormal kidneys (right). Normal kidneys have a distinct border between the medulla and the cortex, with the cortex shown in a darker pink/red color and the medulla shown in a lighter pink color. This indicates that normal blood perfusion was taking place. Abnormal kidneys were either both pale and hypoperfused (middle) or damaged (right), with no clear distinction between the cortex and the medulla. $\mathbf{d}$ One hundred percent of mice in the +TET group have abnormal kidney morphologies, whereas only $25 \%$ of the mice in the - TET group have abnormal kidneys. ${ }^{* *} p<$ 0.01 by Fisher's exact test. e Sera from mice with abnormal kidneys have a statistically significant higher level of OSM than sera from mice with normal kidneys. Data are expressed as mean \pm SEM. ${ }^{*} p<0.05,{ }^{* *} p<0.01$, and ${ }^{* *} p<0.001$ by two-tailed Student's $t$ test. (ZIP $135 \mathrm{~kb}$ )

Additional file 5: Figure S4. OSM is highly expressed in orthotopic 4T1.2 primary mammary tumors in female BALB/c mice. Histology using H\&E confirmed the presence of a large primary mammary tumor (T) 32 days after 4T1.2 mouse mammary tumor cell injection into the fourth mammary fat pad of female BALB/C mice. High OSM expression is seen in the tumor, as is background expression in the normal breast connective tissue (CT). OSM expression is shown to be highest in the invasive edge of the tumor (T) closest to the normal breast connective tissue (CT). Control slides with no primary OSM antibody show low background staining. (PPTX $315 \mathrm{~kb}$ )

Additional file 6: Figure S5. $\mathrm{qPCR}$ analysis of lung metastases after intracardiac injections. 4T1.2-shLacZ cells and 4T1.2-shOSM2 cells were introduced via intracardiac injection, and $\mathrm{QPCR}$ analysis of the lung metastases indicated that the difference between the groups was not significant by two-tailed Student's $t$ test. (ZIP $60 \mathrm{~kb}$ )

Additional file 7: Figure S6. Control colony-forming assay results derived from non-tumor-bearing mice. Blood from non-tumor-bearing mice contained no cells that formed colonies. (PPTX $53 \mathrm{~kb}$ )

Additional file 8: Figure S7. Test of cell line-specific variance in colonyforming assay between 4T1.2-shLacZ and 4T1.2-shOSM2 cell lines. Approximately 10 and 50 cells of 4 T1.2-shLacZ or 4T1.2-shOSM2 cells were seeded onto tissue culture plates and were allowed to incubate until colony formation. No significant differences between the cells were detected with $\sim 10$ cells seeded; however, there was a small but significant increase in the number of colonies with 4T1.2-shOSM2 cells at 50 cells seeded. Data are expressed as mean \pm SEM. ${ }^{*} p<0.05$ by one-way ANOVA with Bonferroni's multiple comparisons test. (PPTX $68 \mathrm{~kb}$ )

Additional file 9: Figure S8. OSM inhibits proliferation of 4T1.2 cells. One hundred $4 T 1.2$ cells were plated at day 0 and treated with $25 \mathrm{ng} / \mathrm{ml}$ of OSM. By day 7, there was a $20 \%$ reduction in total cell numbers in the OSM-treated group versus the non-OSM-treated group. Data are expressed as mean \pm SEM. ${ }^{*} p<0.05,{ }^{* *} p<0.01$; statistical analysis was performed for each day using a two-tailed Student's $t$ test. (PPTX $21 \mathrm{~kb}$ )

\section{Acknowledgements}

The authors thank the Boise Veterans Affairs Medical Center (Boise, ID, USA), as well as the Boise State Biomedical Research Vivarium Core for use of its animal facility

\section{Funding}

This study was partially funded by the following grants: National Institutes of Health (NIH) grants R15CA137510, P20RR016454, P20GM103408, P20GM109095, and P30CA091842, Susan G. Komen grant KG100513, and American Cancer Society grant RSG-09-276-01-CSM.

\section{Availability of data and materials}

All data reported in this article are freely available from the corresponding author on request.

\section{Authors' contributions}

All authors contributed substantially to the concept of this study and the work presented in this paper. KT made a substantial contribution to the writing and editing of the manuscript and helped to do the experiments presented in Figs. 2, 3, 5, and 6 as well as Additional file 3: Figure S2. KT designed and constructed Fig. 7. CB and JK made substantial contributions to the writing of the manuscript helped to generate data shown in Figs. 3 and 5 and Additional file 2: Figures S3 and Additional file 4: Figure S2. SK, JK, and LB generated the data and statistical analysis presented in Fig. 1. $\mathrm{HC}$ and CS generated some of the data presented in Fig. 6. CB and JRG generated the data shown in Fig. 4. Cᄂ provided conceptual guidance for all aspects of the 
project as the principal investigator. All authors read and approved the final manuscript.

\section{Ethics approval}

Breast tissue that was analyzed for this publication was obtained from paraffin block archives at the Department of Pathology, Mercy Medical Center, Nampa, ID, USA, and de-identified, as per their institutional review board's guidelines. All animal experiments were approved by and performed in accordance with the animal guidelines of the Boise Veterans Affairs Medical Center (number JORO010-2) and Boise State University (number 006-AC16-007) institutional animal care and use committees.

\section{Consent for publication}

This article does not contain any individuals' personally identifiable information.

\section{Competing interests}

The authors declare that they have no competing interests.

\section{Publisher's Note}

Springer Nature remains neutral with regard to jurisdictional claims in published maps and institutional affiliations.

\section{Author details}

'Department of Biological Sciences, Biomolecular Sciences Program, Boise State University, 1910 University Drive, Boise, ID 83725, USA. ${ }^{2}$ Mercy Medical Center, Nampa, ID, USA. ${ }^{3}$ Mallinckrodt Institute of Radiology, Washington University, St. Louis, MO 63110, USA.

\section{Received: 5 December 2017 Accepted: 21 April 2018}

\section{Published online: 14 June 2018}

\section{References}

1. Lange C, Storkebaum E, de Almodovar CR, Dewerchin M, Carmeliet P. Vascular endothelial growth factor: a neurovascular target in neurological diseases. Nat Rev Neurol. 2016;12(8):439-54.

2. West NR, McCuaig S, Franchini F, Powrie F. Emerging cytokine networks in colorectal cancer. Nat Rev Immunol. 2015;15(10):615-29.

3. Harris HR, Willett WC, Vaidya RL, Michels KB. An adolescent and early adulthood dietary pattern associated with inflammation and the incidence of breast cancer. Cancer Res. 2017;77(5):1179-87.

4. Chang Q, Bournazou E, Sansone P, Berishaj M, Gao SP, Daly L, Wels J, Theilen T, Granitto S, Zhang X, et al. The IL-6/JAK/Stat3 feed-forward loop drives tumorigenesis and metastasis. Neoplasia. 2013;15(7):848-62.

5. West NR, Hegazy AN, Owens BMJ, Bullers SJ, Linggi B, Buonocore S, Coccia M, Görtz D, This S, Stockenhuber K, et al. Oncostatin M drives intestinal inflammation and predicts response to tumor necrosis factor-neutralizing therapy in patients with inflammatory bowel disease. Nat Med. 2017;23(5): 579-89.

6. Hui W, Rowan AD, Richards CD, Cawston TE. Oncostatin M in combination with tumor necrosis factor alpha induces cartilage damage and matrix metalloproteinase expression in vitro and in vivo. Arthritis Rheum. 2003; 48(12):3404-18

7. Bolin C, Tawara K, Sutherland C, Redshaw J, Aranda P, Moselhy J, Anderson $\mathrm{R}$, Jorcyk CL. Oncostatin M promotes mammary tumor metastasis to bone and osteolytic bone degradation. Genes Cancer. 2012;3(2):117-30.

8. García-Tuñón I, Ricote M, Ruiz A, Fraile B, Paniagua R, Royuela M. OSM, LIF, its receptors, and its relationship with the malignance in human breast carcinoma (in situ and in infiltrative). Cancer Investig. 2008:26(3):222-9.

9. Queen MM, Ryan RE, Holzer RG, Keller-Peck CR, Jorcyk CL. Breast cancer cells stimulate neutrophils to produce oncostatin M: potential implications for tumor progression. Cancer Res. 2005;65(19):8896-904.

10. Tripathi C, Tewari BN, Kanchan RK, Baghel KS, Nautiyal N, Shrivastava R, Kaur $\mathrm{H}$, Bhatt ML, Bhadauria S. Macrophages are recruited to hypoxic tumor areas and acquire a pro-angiogenic M2-polarized phenotype via hypoxic cancer cell derived cytokines oncostatin M and eotaxin. Oncotarget. 2014;5(14): 5350-68.

11. Ryan RE, Martin B, Mellor L, Jacob RB, Tawara K, McDougal OM, Oxford JT, Jorcyk CL. Oncostatin M binds to extracellular matrix in a bioactive conformation: implications for inflammation and metastasis. Cytokine. 2015: $72(1): 71-85$
12. Walker EC, Johnson RW, Hu Y, Brennan HJ, Poulton IJ, Zhang JG, Jenkins BJ, Smyth GK, Nicola NA, Sims NA. Murine oncostatin M acts via leukemia inhibitory factor receptor to phosphorylate signal transducer and activator of transcription 3 (STAT3) but not STAT1, an effect that protects bone mass. J Biol Chem. 2016;291(41):21703-16.

13. Smith DA, Kiba A, Zong Y, Witte ON. Interleukin-6 and oncostatin-M synergize with the PI3K AKT pathway to promote aggressive prostate malignancy in mouse and human tissues. Mol Cancer Res. 2013;11(10): 1159-65.

14. Junk DJ, Bryson BL, Smigiel JM, Parameswaran N, Bartel CA, Jackson MW. Oncostatin M promotes cancer cell plasticity through cooperative STAT3SMAD3 signaling. Oncogene. 2017;36(28):4001-13.

15. Heinrich PC, Behrmann I, Haan S, Hermanns HM, Müller-Newen G, Schaper F. Principles of interleukin (IL)-6-type cytokine signalling and its regulation. Biochem J. 2003;374(Pt 1):1-20.

16. West NR, Murphy LC, Watson PH. Oncostatin M suppresses oestrogen receptor-a expression and is associated with poor outcome in human breast cancer. Endocr Relat Cancer. 2012;19(2):181-95.

17. Humbert L, Ghozlan M, Canaff L, Tian J, Lebrun JJ. The leukemia inhibitory factor (LIF) and p21 mediate the TGF $\beta$ tumor suppressive effects in human cutaneous melanoma. BMC Cancer. 2015:15:200.

18. Johnson RW, Finger EC, Olcina MM, Vilalta M, Aguilera T, Miao Y, Merkel AR, Johnson JR, Sterling JA, Wu JY, et al. Induction of LIFR confers a dormancy phenotype in breast cancer cells disseminated to the bone marrow. Nat Cell Biol. 2016;18(10):1078-89.

19. Kortylewski M, Heinrich PC, Mackiewicz A, Schniertshauer U, Klingmuller U Nakajima K, Hirano T, Horn F, Behrmann I. Interleukin-6 and oncostatin Minduced growth inhibition of human A375 melanoma cells is STATdependent and involves upregulation of the cyclin-dependent kinase inhibitor p27/Kip1. Oncogene. 1999;18(25):3742-53.

20. West NR, Murray Jl, Watson PH. Oncostatin-M promotes phenotypic changes associated with mesenchymal and stem cell-like differentiation in breast cancer. Oncogene. 2014;33(12):1485-94.

21. Jorcyk CL, Holzer RG, Ryan RE. Oncostatin M induces cell detachment and enhances the metastatic capacity of T-47D human breast carcinoma cells. Cytokine. 2006;33(6):323-36.

22. Holzer RG, Ryan RE, Tommack M, Schlekeway E, Jorcyk CL. Oncostatin $M$ stimulates the detachment of a reservoir of invasive mammary carcinoma cells: role of cyclooxygenase-2. Clin Exp Metastasis. 2004; 21(2):167-76

23. Fossey SL, Bear MD, Kisseberth WC, Pennell M, London CA. Oncostatin M promotes STAT3 activation, VEGF production, and invasion in osteosarcoma cell lines. BMC Cancer. 2011:11:125

24. Vollmer S, Kappler V, Kaczor J, Flügel D, Rolvering C, Kato N, Kietzmann T, Behrmann I, Haan C. Hypoxia-inducible factor 1alpha is up-regulated by oncostatin $\mathrm{M}$ and participates in oncostatin M signaling. Hepatology. 2009; 50(1):253-60.

25. Guihard P, Boutet MA, Brounais-Le Royer B, Gamblin AL, Amiaud J, Renaud A, Berreur M, Redini F, Heymann D, Layrolle P, et al. Oncostatin M, an inflammatory cytokine produced by macrophages, supports intramembranous bone healing in a mouse model of tibia injury. Am J Pathol. 2015;185(3):765-75.

26. Lelekakis M, Moseley JM, Martin TJ, Hards D, Williams E, Ho P, Lowen D, Javni J, Miller FR, Slavin J, et al. A novel orthotopic model of breast cancer metastasis to bone. Clin Exp Metastasis. 1999;17(2):163-70.

27. Bolin C, Sutherland C, Tawara K, Moselhy J, Jorcyk CL. Novel mouse mammary cell lines for in vivo bioluminescence imaging (BLI) of bone metastasis. Biol Proced Online. 2012;14(1):6.

28. Martin-Padura I, Marighetti P, Gregato G, Agliano A, Malazzi O, Mancuso P, Pruneri G, Viale A, Bertolini F. Spontaneous cell fusion of acute leukemia cells and macrophages observed in cells with leukemic potential. Neoplasia. 2012:14(11):1057-66.

29. Eckhardt BL, Parker BS, van Laar RK, Restall CM, Natoli AL, Tavaria MD, Stanley KL, Sloan EK, Moseley JM, Anderson RL. Genomic analysis of a spontaneous model of breast cancer metastasis to bone reveals a role for the extracellular matrix. Mol Cancer Res. 2005;3(1):1-13.

30. Livak KJ, Schmittgen TD. Analysis of relative gene expression data using realtime quantitative PCR and the $2^{-\Delta \Delta C}$ T Method. Methods. 2001;25(4):402-8.

31. Garbow JR, Dugas JP, Song S-K, Conradi MS. A simple, robust hardware device for passive or active respiratory gating in MRI and MRS experiments. Concepts Magn Reson Part B: Magn Reson Eng. 2004;21B(1):40-8. 
32. Krupnick AS, Tidwell VK, Engelbach JA, Alli W, Nehorai A, You M, Vikis HG, Gelman AE, Kreisel D, Garbow JR. Quantitative monitoring of mouse lung tumors by magnetic resonance imaging. Nat Protoc. 2012;7(1):128-42.

33. Garbow JR, Wang M, Wang Y, Lubet RA, You M. Quantitative monitoring of adenocarcinoma development in rodents by magnetic resonance imaging. Clin Cancer Res. 2008:14(5):1363-7.

34. Holliday DL, Speirs V. Choosing the right cell line for breast cancer research. Breast Cancer Res. 2011;13(4):215.

35. Jenkins DE, Hornig YS, Oei Y, Dusich J, Purchio T. Bioluminescent human breast cancer cell lines that permit rapid and sensitive in vivo detection of mammary tumors and multiple metastases in immune deficient mice. Breast Cancer Res. 2005;7(4):R444-54.

36. Mak RH, Ikizler AT, Kovesdy CP, Raj DS, Stenvinkel P, Kalantar-Zadeh K. Wasting in chronic kidney disease. J Cachexia Sarcopenia Muscle. 2011;2(1):9-25.

37. Kato Y, Ozawa S, Miyamoto C, Maehata Y, Suzuki A, Maeda T, Baba Y. Acidic extracellular microenvironment and cancer. Cancer Cell Int. 2013;13(1):89.

38. Liu J, Hadjokas N, Mosley B, Estrov Z, Spence MJ, Vestal RE. Oncostatin Mspecific receptor expression and function in regulating cell proliferation of normal and malignant mammary epithelial cells. Cytokine. 1998;10(4):295-302.

39. Somlo G, Lau SK, Frankel P, Hsieh HB, Liu X, Yang L, Krivacic R, Bruce RH. Multiple biomarker expression on circulating tumor cells in comparison to tumor tissues from primary and metastatic sites in patients with locally advanced/inflammatory, and stage IV breast cancer, using a novel detection technology. Breast Cancer Res Treat. 2011;128(1):155-63.

40. Putzbach W, Gao QQ, Patel M, van Dongen S, Haluck-Kangas A, Sarshad AA Bartom ET, Kim KA, Scholtens DM, Hafner M, et al. Many si/shRNAs can kill cancer cells by targeting multiple survival genes through an off-target mechanism. Elife. 2017:6:e29702.

41. Ramji K, Kulesza DW, Chouaib S, Kaminska B. Off-target effects of plasmidtranscribed shRNAs on NFkB signaling pathway and cell survival of human melanoma cells. Mol Biol Rep. 2013;40(12):6977-86.

42. Buehler E, Khan AA, Marine S, Rajaram M, Bahl A, Burchard J, Ferrer M. siRNA off-target effects in genome-wide screens identify signaling pathway members. Sci Rep. 2012;2:428

43. Liu H, Zhang X, Li J, Sun B, Qian H, Yin Z. The biological and clinical importance of epithelial-mesenchymal transition in circulating tumor cells. J Cancer Res Clin Oncol. 2015;141(2):189-201.

44. Murray II, West NR, Murphy LC, Watson PH. Intratumoural inflammation and endocrine resistance in breast cancer. Endocr Relat Cancer. 2015;22(1):R51-67.

45. Hosseini $\mathrm{H}$, Obradović MM, Hoffmann M, Harper KL, Sosa MS, Werner-Klein M, Nanduri LK, Werno C, Ehrl C, Maneck M, et al. Early dissemination seeds metastasis in breast cancer. Nature. 2016;540:552-8.

46. Hazlett LD, Berk RS. Heightened resistance of athymic, nude (nu/nu) mice to experimental Pseudomonas aeruginosa ocular infection. Infect Immun. 1978; 22(3):926-33.

47. Koch J, Hau J, Pravsgaard Christensen J, Elvang Jensen H, Bagge Hansen M, Rieneck K. Immune cells from SR/CR mice induce the regression of established tumors in BALB/C and C57BL/6 mice. PLoS One. 2013;8(3): e59995

48. Xie J, Zhu S, Dai Q, Lu J, Chen J, Li G, Wu H, Li R, Huang W, Xu B, et al. Oncostatin $\mathrm{M}$ was associated with thrombosis in patients with atrial fibrillation. Medicine (Baltimore). 2017;96(18):e6806

49. Lauber S, Wong S, Cutz JC, Tanaka M, Barra N, Lhotak S, Ashkar A, Richards CD. Novel function of oncostatin $\mathrm{M}$ as a potent tumour-promoting agent in lung. Int J Cancer. 2015;136(4):831-43.

50. Tisdale MJ. Mechanisms of cancer cachexia. Physiol Rev. 2009;89(2):381-410.

51. Kholmukhamedov A, Czerny C, Hu J, Schwartz J, Zhong Z, Lemasters JJ. Minocycline and doxycycline, but not tetracycline, mitigate liver and kidney injury after hemorrhagic shock/resuscitation. Shock. 2014;42(3): 256-63.

52. Lokeshwar BL, Selzer MG, Zhu BQ, Block NL, Golub LM. Inhibition of cell proliferation, invasion, tumor growth and metastasis by an oral nonantimicrobial tetracycline analog $(\mathrm{COL}-3)$ in a metastatic prostate cancer model. Int J Cancer. 2002;98(2):297-309.

53. Miller A, McLeod L, Alhayyani S, Szczepny A, Watkins DN, Chen W, Enriori $P$, Ferlin W, Ruwanpura S, Jenkins BJ. Blockade of the IL-6 trans-signalling/ STAT3 axis suppresses cachexia in Kras-induced lung adenocarcinoma. Oncogene. 2017;36(21):3059-66.

54. Onesti JK, Guttridge DC. Inflammation based regulation of cancer cachexia. Biomed Res Int. 2014:2014:168407.
55. Rao DD, Senzer N, Cleary MA, Nemunaitis J. Comparative assessment of siRNA and shRNA off target effects: what is slowing clinical development. Cancer Gene Ther. 2009;16(11):807-9.

56. Li C, Li J, Li Y, Lang S, Yougbare I, Zhu G, Chen P, Ni H. Crosstalk between platelets and the immune system: old systems with new discoveries. Adv Hematol. 2012;2012:384685.

57. Taucher S, Salat A, Gnant M, Kwasny W, Mlineritsch B, Menzel RC, Schmid M, Smola MG, Stierer M, Tausch C, et al. Impact of pretreatment thrombocytosis on survival in primary breast cancer. Thromb Haemost. 2003;89(6):1098-106

58. Yuan L, Liu X. Platelets are associated with xenograft tumor growth and the clinical malignancy of ovarian cancer through an angiogenesis-dependent mechanism. Mol Med Rep. 2015:11(4):2449-58.

59. Gligorijevic B, Wyckoff J, Yamaguchi H, Wang Y, Roussos ET, Condeelis J. NWASP-mediated invadopodium formation is involved in intravasation and lung metastasis of mammary tumors. J Cell Sci. 2012;125(Pt 3):724-34.

60. Bednarz-Knoll N, Alix-Panabieres C, Pantel K. Clinical relevance and biology of circulating tumor cells. Breast Cancer Res. 2011;13(6):228.

61. Husemann Y, Geigl JB, Schubert F, Musiani P, Meyer M, Burghart E, Forni G, Eils $R$, Fehm T, Riethmuller $G$, et al. Systemic spread is an early step in breast cancer. Cancer Cell. 2008;13(1):58-68.

62. Zhao $S$, Yang $H$, Zhang $M$, Zhang $D$, Liu Y, Liu Y, Song $Y$, Zhang $X$, Li H, Ma W, et al. Circulating tumor cells (CTCS) detected by triple-marker EpCAM, CK19, and hMAM RT-PCR and their relation to clinical outcome in metastatic breast cancer patients. Cell Biochem Biophys. 2013;65(2):263-73.

63. Gorges TM, Tinhofer I, Drosch M, Rose L, Zollner TM, Krahn T, von Ahsen O. Circulating tumour cells escape from EpCAM-based detection due to epithelial-to-mesenchymal transition. BMC Cancer. 2012;12:178.

64. Allan AL, Keeney M. Circulating tumor cell analysis: technical and statistical considerations for application to the clinic. J Oncol. 2010;2010:426218.

65. Tibbe AG, Miller MC, Terstappen LW. Statistical considerations for enumeration of circulating tumor cells. Cytometry A. 2007;71(3):154-62.

66. Tseng JY, Yang CY, Liang SC, Liu RS, Jiang JK, Lin CH. Dynamic changes in numbers and properties of circulating tumor cells and their potential applications. Cancers (Basel). 2014;6(4):2369-86.

67. Tester AM, Ruangpanit N, Anderson RL, Thompson EW. MMP-9 secretion and MMP-2 activation distinguish invasive and metastatic sublines of a mouse mammary carcinoma system showing epithelial-mesenchymal transition traits. Clin Exp Metastasis. 2000;18(7):553-60.

68. Kim MY, Oskarsson T, Acharyya S, Nguyen DX, Zhang XH, Norton L, Massagué J. Tumor self-seeding by circulating cancer cells. Cell. 2009;139(7): 1315-26.

69. Kucia-Tran JA, Tulkki V, Scarpini CG, Smith S, Wallberg M, Paez-Ribes M, Araujo AM, Botthoff J, Feeney M, Hughes $K$, et al. Anti-oncostatin M antibody inhibits the pro-malignant effects of oncostatin $M$ receptor overexpression in squamous cell carcinoma. J Pathol. 2018;244(3):283-95.

70. Caffarel MM, Coleman N. Oncostatin M receptor is a novel therapeutic target in cervical squamous cell carcinoma. J Pathol. 2014;232(4):386-90.

\section{Ready to submit your research? Choose BMC and benefit from:}

- fast, convenient online submission

- thorough peer review by experienced researchers in your field

- rapid publication on acceptance

- support for research data, including large and complex data types

- gold Open Access which fosters wider collaboration and increased citations

- maximum visibility for your research: over $100 \mathrm{M}$ website views per year

At BMC, research is always in progress.

Learn more biomedcentral.com/submissions 